\title{
The SAD1/RAD53 protein kinase controls multiple checkpoints and DNA damage- induced transcription in yeast
}

\author{
James B. Allen, ${ }^{1,2}$ Zheng Zhou, ${ }^{1,2}$ Wolfram Siede, ${ }^{4}$ Errol C. Friedberg, ${ }^{4}$ and Stephen J. Elledge ${ }^{1-3}$ \\ ${ }^{1}$ Howard Hughes Medical Institute, ${ }^{2}$ Verna \& Marrs McLean Department of Biochemistry, ${ }^{3}$ Institute for Molecular Genetics, \\ Baylor College of Medicine, Houston, Texas 77030 USA; ${ }^{4}$ Department of Pathology, University of Texas, Southwestern \\ Medical Center, Dallas, Texas 75235 USA
}

\begin{abstract}
Inhibition of DNA synthesis prevents mitotic entry through the action of the S-phase checkpoint. We have isolated S-phase arrest-defective ( $\mathbf{s a d}$ ) mutants that show lethality in the presence of the DNA synthesis inhibitor hydroxyurea (HU). Several of these mutants show phenotypes consistent with inappropriate mitotic entry in the presence of unreplicated DNA, indicating a defect in the S-phase checkpoint. sad1 mutants are additionally defective for the $G_{1}$ and $G_{2}$ DNA damage checkpoints, and for DNA damage-induced transcription of $R N R 2$ and $R N R 3$. The transcriptional response to DNA damage requires activation of the Dun1 protein kinase. Activation of Dun1 in response to replication blocks or DNA damage is blocked in sad1 mutants. The HU sensitivity of sad1 mutants is suppressed by mutations in CKS1, a subunit of the p34 ${ }^{\text {CDC28 }}$ kinase, further establishing a link between cell cycle progression and lethality. sad1 mutants are allelic to rad53, a radiation-sensitive mutant. SAD1 encodes an essential protein kinase. The observation that SAD1 controls three distinct checkpoints suggests a common mechanism for cell cycle arrest at these points. Together, these observations implicate protein phosphorylation in the cellular response to DNA damage and replication blocks.
\end{abstract}

[Key Words: Protein kinase; DNA damage; transcription; yeast; protein phosphorylation]

Received July 14, 1994; revised version accepted August 19, 1994.

A successful eukaryotic cell division requires that certain cellular processes occur in a defined order and are coupled so that the initiation of one event is dependent on the completion of another. In most cell types, entry into mitosis is dependent on the completion of DNA synthesis. Cells blocked for DNA replication arrest in S phase and delay mitotic initiation. Cell cycle arrest in response to S-phase inhibition is attributable to the presence of a feedback control or checkpoint mechanism /for reviews on cell cycle checkpoints, see Hartwell and Weinert 1989; Enoch and Nurse 1991; Murray 1992; Roberge 1992; Li and Deshaies 1993). Checkpoint controls also provide regulation of cell cycle progression in response to environmental challenges such as DNA damage. Cellular responses to DNA damage and blocks in DNA replication are similar: Cells arrest progression through the cell cycle at distinct points and induce the transcription of genes whose products facilitate DNA repair. In response to DNA damage, eukaryotic cells arrest either in $G_{1}$ to prevent replication of damaged genetic templates or in $G_{2}$ to avoid segregation of defective chromosomes. A current point of interest is whether feedback controls also order events in a normal cell cycle in the absence of DNA damage or replication blocks. In this regard it has been proposed that relative timing mecha- nisms may order events in a normal cell cycle and that cell cycle arrest checkpoints are activated to ensure dependencies in cases when relative timing is insufficient (Murray 1992; Li and Deshaies 1993).

Defects in cell cycle checkpoints can result in genomic instability and increase the rate that cells accumulate heritable genetic damage. In budding yeast, mutations exist that exhibit elevated levels of chromosome loss and are unable to arrest the cell cycle in $\mathrm{G}_{1}$ (Siede et al. 1993) or $G_{2}$ (Weinert and Hartwell 1988; Weinert et al. 1994) in response to DNA damage. Among these, the mec1 and mec2 mutants have been implicated in the S-phase checkpoint because of sensitivity to conditions resulting in replication blocks and abnormal spindle structures in the presence of hydroxyurea $(\mathrm{HU})$ (Weinert et al. 1994). However, a definitive role in the S-phase checkpoint has not yet been established for these mutants because cells can leak through a HU block, and it was not demonstrated that these mutants entered mitosis with DNA that was less than fully replicated. Strains lacking feedback controls that couple spindle assembly and exit from mitosis also lose chromosomes at a higher rate than wild-type cells (Hoyt et al. 1991; Li and Murray 1991). Furthermore, it has been suggested that checkpoint control deficiency in mammalian cells may play a 
role in cellular transformation (Hartwell 1992; Livingstone et al. 1992; Kastan et al. 1992; Murray 1992; Yin et al. 1992). Ataxia-telangiectasia (AT) is a human recessive disorder characterized by a number of phenotypes including a high incidence of cancer. Cell lines derived from AT patients are defective for both the $G_{1}$ and $G_{2}$ DNA damage checkpoints (Painter and Young 1980; Zambetti-Bosseler and Scott 1981; Nagasawa et al. 1985; Cohen and Levy 1989; Rudolph and Latt 1989). In addition, primary murine fibroblasts that carry null or mutant alleles of the tumor suppressor gene p53 fail to arrest the cell cycle in $G_{1}$ in response to ionizing radiation (Kuerbitz et al. 1992; Yin et al. 1992) and are defective for the DNA damage-induced transcription of CIP1/WAF1 (El Diery et al. 1993, 1994), an inhibitor of Cdk2 and Cdk4 (Gu et al. 1993; Harper et al. 1993; Xiong et al. 1993). Taken together, these observations suggest that the inability to respond to DNA damage by cell cycle arrest or to induce transcription of genes that facilitate DNA repair may potentiate cellular transformation.

A number of checkpoint mutants have been identified in a variety of species; however, the biochemical nature of the cell's ability to coordinate cell cycle progression with the replicational status and integrity of the genome remains unclear. The eukaryotic cell cycle is composed of two major transitions, one at the $G_{1} / S$ boundary and another at $\mathrm{G}_{2} / \mathrm{M}$. These transitions are controlled by the p34 protein kinase and associated regulatory subunits called cyclins. The p34/cyclin complex is an attractive target for checkpoint inhibition. In Schizosaccharomyces pombe, cells treated with the chemical HU are blocked for DNA replication and maintain high levels of inhibitory Tyr-15 phosphorylation on $\mathrm{p} 34^{\text {cdc2 }}$ /Gould and Nurse 1989; Nurse 1990). Cells that contain an unphosphorylatable mutant of $\mathrm{p} 34^{c d c 2}, \mathrm{Y} 15 \mathrm{~F}$, bypass the cell cycle arrest imposed by unreplicated DNA and enter a lethal mitosis (Gould and Nurse 1989). It is not yet clear whether the dominant cdc2:Y15F mutant functions indirectly by bypassing the checkpoint, or directly by blocking its target, phosphorylation of Tyr-15. In contrast, Saccharomyces cerevisiae strains that contain an analogous mutation on $\mathrm{p} 34^{\mathrm{CDC} 28}$ are competent to respond to S-phase inhibition and progress normally through the cell cycle (Amon et al. 1992; Sorger and Murray 1992). This suggests that budding yeast possess a mode of checkpoint control distinct from inhibitory tyrosine phosphorylation of $\mathrm{p} 34$.

Although progress has been made in understanding cell cycle checkpoints and the cellular response to DNA damage, several outstanding questions remain. First, what is the molecular nature of the S-phase checkpoint? Second, does it operate during an unperturbed cell cycle or only in response to stress? Third, is there overlap between the DNA damage checkpoint pathways in $G_{1}$ and $\mathrm{G}_{2}$ and the S-phase checkpoint pathway? Fourth, to what extent do the cell cycle arrest and DNA damage transcriptional induction pathways overlap? To address these questions and elucidate the signaling pathway coordinating $S$ phase and mitosis, we have focused on the isolation of S-phase arrest-defective (sad) mutants that disrupt cell cycle arrest in response to blocks in DNA replication.

\section{Results}

\section{Isolation of sad mutants}

HU inhibits the enzyme ribonucleotide reductase (Rnr) by quenching the tyrosyl free radical required for catalysis. Inhibition of Rnr results in the inability to synthesize deoxyribonucleotides, which blocks DNA synthesis. Wild-type cells respond to HU treatment by reversibly arresting cell cycle progression through activation of the S-phase checkpoint. Mutations in the S-phase checkpoint pathway should confer sensitivity to HU because the inability to delay cell cycle progression may result in mitosis in the absence of DNA replication. EMS-mutagenized colonies $(250,000)$ were replica-plated to plates containing $100 \mathrm{~mm} \mathrm{HU}$, and $\sim 700 \mathrm{HU}$-sensitive mutants were isolated. To specifically identify sad mutants, two secondary screens were employed. First, HU-sensitive mutants were screened for loss of viability in the presence of $\mathrm{HU}$ (HU reversibility) by replica-plating and liquid survival assays, and second, for rescue by prior arrest with $\alpha$-factor as described in Materials and methods. sad mutants should exhibit rapid loss of viability in the presence of $\mathrm{HU}$ because of their inability to delay cell cycle progression when DNA synthesis is inhibited. In addition, HU-induced lethality should be suppressed by prior treatment with $\alpha$-factor, which arrests cells in $G_{1}$ and prevents inappropriate cell cycle progression. Six recessive mutants representing five different complementation groups, sad1-sad5, were isolated that exhibit rapid loss of viability with HU that is $\alpha$-factor suppressible. sad mutants display significant killing after $6 \mathrm{hr}$ of $\mathrm{HU}$ treatment compared with wild-type controls (Fig. 1A). In addition, sad mutants are significantly more sensitive to UV-irradiation than wild-type strains (Fig. 1B). This suggests that sad mutants may be additionally defective for DNA repair or the DNA damage cell cycle checkpoints. sad1-1 mutants exhibit the most rapid lethality and were selected for further analysis. $\alpha$-Factor suppression of sad1-1 HU lethality is shown in Figure 1C.

\section{Screen of rad mutants for S-phase feedback control deficiency}

Mutants defective for DNA damage-induced cell cycle arrest have been identified among preexisting collections of mutations that confer radiation sensitivity in budding yeast and fission yeast (rad mutants) (Weinert and Hartwell 1988; Al-Khodairy and Carr 1992; Enoch et al. 1992; Rowley et al. 1992; Weinert 1992). It is also likely that the DNA damage and the S-phase checkpoint pathways share common components (Al-Khodairy and Carr 1992; Enoch et al. 1992; Weinert 1992). In this regard, a bank of budding yeast rad mutants were screened for the sad phenotype. As shown in Table 1, rad50, rad51, and rad53 mutants exhibit some sad phenotypes. sad mutants 

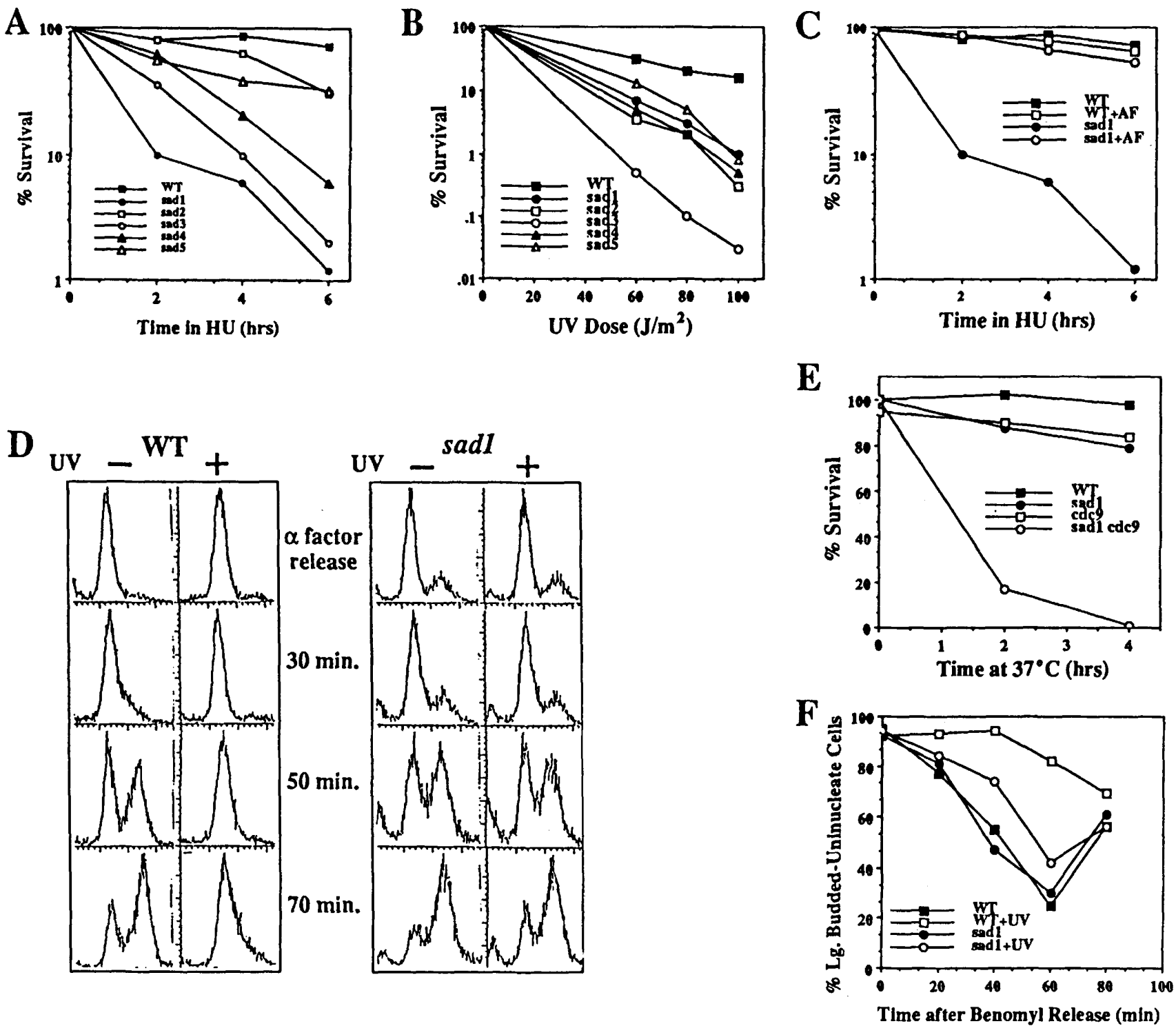

Figure 1. Checkpoint deficiency and radiation sensitivity of sad mutants. $(A)$ HU lethality of wild-type and sad strains. Wild-type strain Y300 ( $\square$ ) and sad mutant cells (Y301, sad1-1, ; Y305, sad2-1, $\square$; Y306, sad3-1, O; Y307, sad4-1, $\mathbf{\Delta}$; and Y308, sad5-1, $\triangle$ ) were grown to $\log$ phase in YPD (pH 3.9), and $\mathrm{HU}$ was added to $0.2 \mathrm{M}$. Aliquots were removed at timed intervals to determine cell number and to score for viable colony-forming units on YPD plates. (B) Radiation sensitivity of sad mutants. Wild-type (Y300, SAD1, $\mathbf{a}$ ) and sad mutant cells (Y301, sad1-1, ; Y305, sad2-1, $\square$; Y306, sad3-1, O; Y307, sad4-1, $\boldsymbol{\Delta}_{\text {; }}$ and Y308, sad5-1, $\Delta$ ) were irradiated with the indicated doses of UV light, and percent survival relative to unirradiated controls was determined. (C) $\alpha$-Factor rescue of sad1-1 cells. Log-phase cultures were treated with $10 \mu \mathrm{g} / \mathrm{ml}$ of $\alpha$-factor for $1 \mathrm{hr}$. Samples were washed with YPD, split, and resuspended in YPD containing $0.2 \mathrm{M} \mathrm{HU}$ (Y300, wild-type, $\mathbf{\square}$; Y301, sad1-1, $)$ ) or $0.2 \mathrm{M} \mathrm{HU}$ plus $10 \mu \mathrm{g} / \mathrm{ml}$ of $\alpha$-factor (Y300, wild-type, $\square$; Y301, sad1-1, O|. $\alpha$-Factor $(2 \mu \mathrm{g} / \mathrm{ml})$ was subsequently added every $2 \mathrm{hr}$ to $\alpha$-factor-treated samples. $(D)$ DNA damage-induced $\mathrm{G}_{1}$ cell cycle delay in SAD and sad1-1. Wild-type Y300 (left) and sad1-1 Y301 (right) strains were synchronized with $\alpha$-factor and UV-irradiated. Unirradiated $(-)$ and irradiated $(+)$ samples were resuspended into fresh YPD media, and cell cycle progression was monitored by FACS analysis. Numbers in the center refer to the time in minutes after release from $\alpha$-factor block. $(E)$ Survival of $c d c 9$ sad1 double mutants at the restrictive temperature. Wild-type strain Y300(口), Y301 sad1-1(O), Y309 cdc9(口), and Y310 cdc9 sad1 double mutants (O) were grown to $\log$ phase at $23^{\circ} \mathrm{C}$ and shifted to $37^{\circ} \mathrm{C}$ for $4 \mathrm{hr}$. Dilutions were plated at timed intervals and incubated at $23^{\circ} \mathrm{C}$ to determine cell viability. $(F)$ DNA damage-induced $\mathrm{G}_{2}$ cell cycle delay in wild-type and sad1-1 strains. Wild-type strain $\mathrm{Y} 300$ ( $\square$, $\square$ ) and $\mathrm{Y} 301$ sad1-1 cells $(0,0)$ were arrested with $100 \mu \mathrm{g} / \mathrm{ml}$ of benomyl and UV-irradiated. Unirradiated $(\mathbf{\square}, 0)$ and $U V$-irradiated $\left(40 \mathrm{~J} / \mathrm{m}^{2}, 0\right.$, ㅁ) samples were resupended into fresh media, and cell cycle progression was monitored by direct visualization of nuclear division using DAPI staining.

were crossed with rad50, rad51, and rad53 to test for complementation and linkage. rad53 is allelic to sad1 while rad50 and rad51 are not allelic to any of the sad mutants. 
Table 1. Screen of rad mutants for sad phenotype

\begin{tabular}{llll}
\hline & \multicolumn{2}{c}{ HU } & HU lethality \\
\cline { 2 - 3 } Mutant & sensitive & reversible & \\
suppressed by $\alpha$-factor \\
\hline rad5 & no & & \\
rad8 & no & & \\
rad14 & no & & \\
rad16 & no & & \\
rad23 & no & & \\
rad24 & no & & yes \\
rad50 & yes & no & yes \\
rad51 & yes & no & yes \\
rad52 & yes & yes & \\
rad53 & yes & no & \\
rad54 & yes & yes & \\
rad55 & yes & yes & \\
rad56 & yes & yes & \\
rad57 & yes & yes & \\
\hline A & & & \\
\hline
\end{tabular}

A collection of preexisting rad mutants were screened for $\mathrm{HU}$ sensitivity, $H U$ reversibility, and $\alpha$-factor suppression of $H U$ lethality as described in Materials and methods.

sad1 is deficient for DNA damage-induced cell cycle delay in $G_{1}$ and $G_{2}$

$R A D 9$ is required for cell cycle arrest in response to DNA damage in $G_{1}$ (Siede et al. 1993) and $G_{2}$ (Weinert and Hartwell 1988). In addition, several $c d c$ mutants are dependent on $R A D 9$ for their $c d c$ phenotypes and arrest reversibilities. For example, temperature-sensitive mutants in $c d c 9$, encoding DNA ligase, arrest in $\mathrm{G}_{2}$ with the bulk of DNA synthesis completed but with unligated Okazaki fragments (Johnston and Nasmyth 1978). cdc9 mutants arrest reversibly at high temperatures, whereas rad9 cdc9 double mutants exhibit rapid loss of viability at the restrictive temperature because of entry into $\mathrm{mi}$ tosis with damaged DNA.

Although RAD9 is not required for the S-phase checkpoint (Elledge and Davis 1990; Weinert and Hartwell 1993), the UV-sensitivity of sad1-1 suggests that SAD1 may have a role in the $R A D$ 9-dependent $\mathrm{G}_{1}$ and $\mathrm{G}_{2} \mathrm{DNA}$ damage checkpoints. To examine the $G_{1}$ DNA damage checkpoint, wild-type and sad1-1 mutant strains were arrested in $G_{1}$ with $\alpha$-factor, UV-irradiated, and released from $\alpha$-factor. Samples were removed at timed intervals to monitor cell cycle progression by measuring DNA content and bud formation. Unirradiated wild-type cells progress normally through the cell cycle following release from $\alpha$-factor while irradiation produces a $G_{1}$ delay (Fig. 1D). In contrast, both untreated and irradiated sad1-1 cells progress through the cell cycle in a similar fashion after release from $\alpha$-factor as measured by both FACS analysis (Fig. 1D) and bud formation (data not shown). These results demonstrate that $S A D 1$ is required for the $G_{1}$ DNA damage cell cycle checkpoint.

To examine the $G_{2}$ DNA damage checkpoint as defined by Weinert and Hartwell (1988), cdc9 sad1 double mutant strains were constructed. As shown in Figure 1E, $c d c 9$ sad1 mutants lose viability at high temperature compared with $c d c 9$ strains, consistent with a defect in DNA damage-induced $G_{2}$ delay. To address this point further, wild-type and mutant strains were synchronized with the microtubule inhibitor benomyl and irradiated. Previous studies have demonstrated that the RAD9-dependent checkpoint can also function at the benomyl block, which is likely to be post- $G_{2}$ in early $M$ phase by analogy to other organisms. Because clear cytological criteria are not available in $S$. cerevisiae to distinguish $\mathrm{G}_{2}$ from early $M$ phase, we refer to this point as $G_{2} / M$ to facilitate discussion. Cells treated with benomyl complete DNA replication but are unable to assemble a mitotic spindle and arrest the cell cycle through the $B U B$ and MAD-dependent checkpoint pathways ( $\mathrm{Li}$ and Murray 1991; Hoyt et al. 1991). After release from benomyl arrest, the kinetics of visible nuclear division are followed (Fig. 1F). Unirradiated wild-type and sad1-1 mutant cells normally progress through mitosis with similar kinetics, whereas irradiated wild-type cells exhibit a UV-induced cell cycle delay relative to unirradiated cells. In contrast, sad1-1 mutants are largely defective for UV-induced cell cycle delay at $\mathrm{G}_{2} / \mathrm{M}$. The residual delay observed in UV-treated sad1-1 mutants may be attributed to the hypomorphic nature of the sad1-1 allele (deletion of SAD1 is lethal). These results show that sad1-1 mutants are also unable to arrest the cell cycle in $G_{2}$ or $G_{2} / M$ in response to DNA damage. Because the phenotypes of $\mathrm{rad} 9$ represent a subset of the sad1-1 phenotypes, it is likely that $S A D 1$ and $R A D 9$ function in the same pathway.

\section{Characterization of the S-phase feedback control deficiency in sad 1}

If sad1-1 strains are completely deficient for $\mathrm{HU}$-induced cell cycle arrest, then the kinetics of spindle elongation in sad1-1 cells after $G_{1}$ release should be similar in the presence or absence of HU. To further understand the S-phase arrest deficiency of sad1-1 mutants, we examined the rate and extent of entry into mitosis (anaphase) in synchronized wild-type and sad1-1 mutant strains. Strains were arrested in $G_{1}$ with $\alpha$-factor and released either into YPD or YPD containing $200 \mathrm{~mm}$ HU. Samples were removed at 15 -min intervals to determine viability, DNA content, and to assess cellular, nuclear, and microtubule morphologies.

When released from $G_{1}$ into media containing $H U$, both wild-type and sad1-1 mutant cells maintain a $\mathrm{G}_{1}$ DNA content (Fig. 2A). Wild-type cells released from $\alpha$-factor into media without HU progress normally through the cell cycle, initially exhibiting spindle elongation and nuclear division $\sim 60 \mathrm{~min}$ after $G_{1}$ release (Fig. 2B). sad1-1 cells released from $G_{1}$ in the absence of HU also progress normally through the cell cycle, although the rate of mitotic entry is slower than wild type. Wild-type cells released into media containing $\mathrm{HU}$ are prevented from entering mitosis and arrest as budded, uninucleate cells with short spindles (Fig. 2B,D). However, in contrast, a significant proportion of sad1-1 cells released from $\mathrm{G}_{1}$ into media containing $\mathrm{HU}$ enter mito- 
A

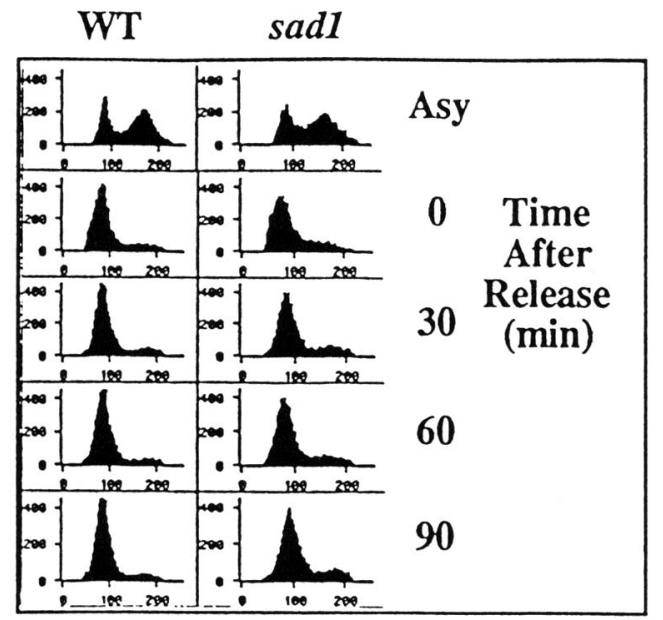

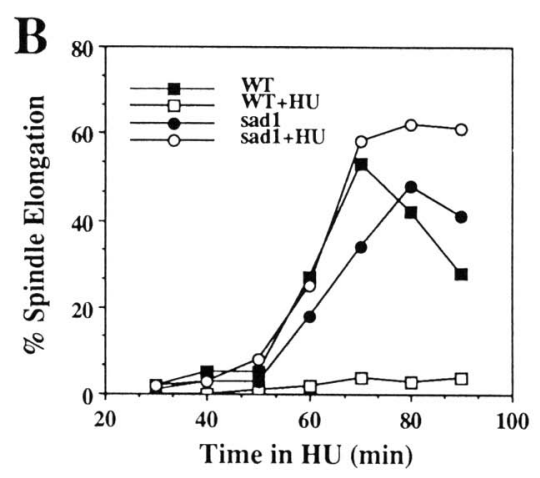

D
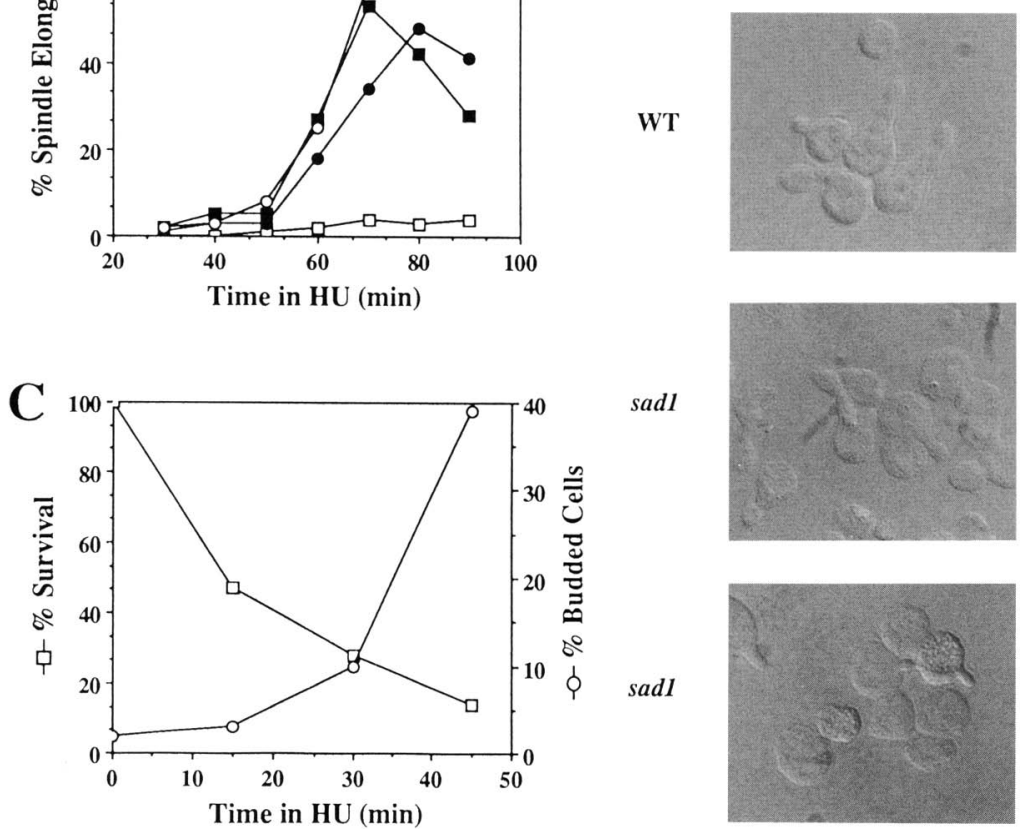

DIC

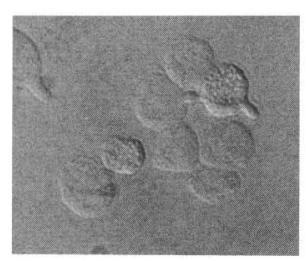

DAPI
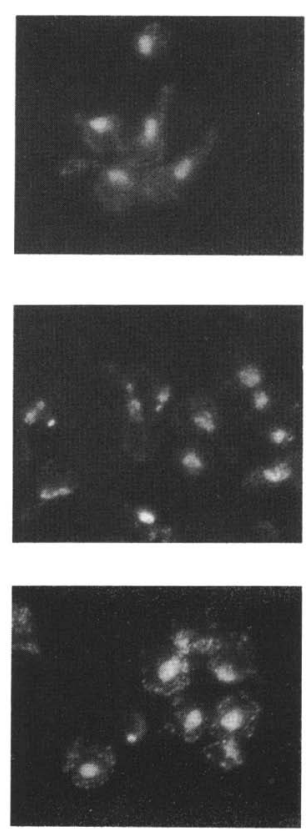

$\alpha$-Tubulin
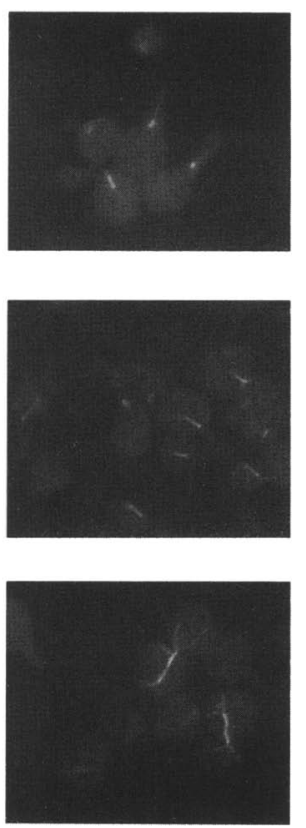

Figure 2. sad1-1 cells exhibit premature spindle elongation in the presence of HU. Wild-type strain (Y300) and sad1-1 (Y301) cells were synchronized in $G_{1}$ with $\alpha$-factor and released into YPD in the presence and absence of HU. $(A)$ DNA content of HU-arrested wild-type and sad1-1 cells measured by FACS analysis. (Asy) Asynchronous cells. Numbers at right represent the time in minutes after release from $\alpha$-factor arrest into YPD containing $200 \mathrm{mM}$ HU. $(B)$ Kinetics of spindle elongation in wild-type $(\square, \square)$ and sad1-1 mutant cells $(0, O)$ released from $G_{1}$ arrest in the presence $(O, \square)$ or absence $(\square, 0)$ of $H U$. Samples were taken at timed intervals as above and stained with antitubulin antibodies, and the percentage of cells that exhibit elongated spindles was determined using indirect immunoflourescence. A typical data set is shown. A statistical analysis of the data gathered from four independent experiments is presented in the text. $(C)$ sad1-1 cells lose viability in late $G_{1}$ and $S$ phase upon $G_{1}$ release in the presence of HU. Dilutions of $\mathrm{G}_{1}$-synchronized sad1-1 cells were plated onto YPD plates at different times after release into $0.2 \mathrm{M} H \mathrm{H}$, and cell viability was determined with respect to $G_{1}$-arrested samples $(\square)$. Samples were also scored for bud emergence $(O)$. (D) Photomicrographs of wild-type and sad1-1 cells 60 min after $G_{1}$ release into HU-containing media. Nuclear morphology was visualized with DAPI (center panels) and microtubule morphology was visualized with anti- $\alpha$-tubulin (right panels) in wild-type (top panels) and sad1-1 cells (middle and bottom rows). sad1 mutants exhibit partially and fully elongated spindles in the presence of HU.

sis as judged by nuclear division and spindle elongation (Fig. 2B,D). Entry into mitosis with incompletely replicated DNA is the defining characteristic of S-phase checkpoint-defective mutants. sad1-1 mutants exhibit a mixture of partially (two- to threefold longer than in HUarrested wild-type) and fully elongated spindles in $\mathrm{HU}$. 
Interestingly, HU-treated sad1-1 cultures accumulate cells with elongated spindles at a rate faster than sad1-1 cells released from $G_{1}$ in the absence of $\mathrm{HU}$ (Fig. 2B). The mean time for $30 \%$ of the cells to exhibit spindle elongation in sad1 mutants in HU was $51.2 \pm 2.4 \mathrm{~min}$, compared with $61.8 \pm 2.5 \mathrm{~min}$ without $\mathrm{HU}$ (averaged over four data sets). Thus, HU accelerates mitotic onset by $10.5 \pm 2.4 \mathrm{~min}$. In addition, sad1-1 cells released in the presence of HU contain a significant proportion of unbudded and small budded cells that possess mitotic spindles (data not shown). Unbudded or small budded cells that contain elongated spindles were not observed in wild-type cultures and were seen only rarely in sad1-1 strains not treated with $\mathrm{HU}$.

sad1-1 cells released from $\mathrm{G}_{1}$ in the presence of $\mathrm{HU}$ quickly lose viability following $G_{1}$ release (Fig. 2 C). Correlation of sad1-1 lethality with cellular morphology indicates that sad1-1 cells lose viability coincident with entry and progression through $\mathrm{S}$ phase. These kinetics are consistent with a commitment to lethality once replication is delayed for a short period of time.

\section{SAD1 is required for the DNA damage inducibility of RNR2 and RNR3}

Both prokaryotic and eukaryotic cells respond to DNA damage by arresting the cell cycle and inducing transcription of genes whose products facilitate DNA repair. We were interested in whether these pathways share common components. To address this, sad1-1 mutants were examined for regulation of the DNA damage-inducible RNR2, RNR3, and UBI4 genes. RNR2 and RNR3 encode the catalytic and an alternative regulatory subunit of ribonucleotide reductase, respectively. UBI4 encodes polyubiquitin. As shown in Figure 3, sad1-1 mutants are defective for methylmethane sulfonate (MMS)induced transcription of $R N R 2$ and $R N R 3$ but are competent for induction of $U B I 4$. This phenotype is similar to that observed for dun1 mutants and supports the observation that multiple pathways exist for transcription induced by DNA damaging agents (Zhou and Elledge 1993).

\section{Sad1 controls the kinase activity of Dun1 in response to DNA damage}

The Dunl protein kinase is required for the DNA damage-induced expression of RNR2 and RNR3 (Zhou and Elledge 1993). Dunl is activated in response to DNA damage as evidenced by the DNA damage-dependent generation of slower migrating forms of Dunl in in vitro autophosphorylation assays and an increase in DUN1. dependent autophosphorylation in vivo. While DUN1 is required for the transcriptional response to DNA damage, it is not required for the $\mathrm{G}_{1^{-}}, \mathrm{G}_{2^{-}}$, or S-phase checkpoints. sad1 mutants are defective for both DNA damage-induced cell cycle arrest and transcription of RNR2 and $R N R 3$. It is therefore likely that $S A D 1$ functions in the same pathway as $D U N 1$. Because $S A D 1$ also controls cell cycle checkpoints and DUN1 does not, it is possible

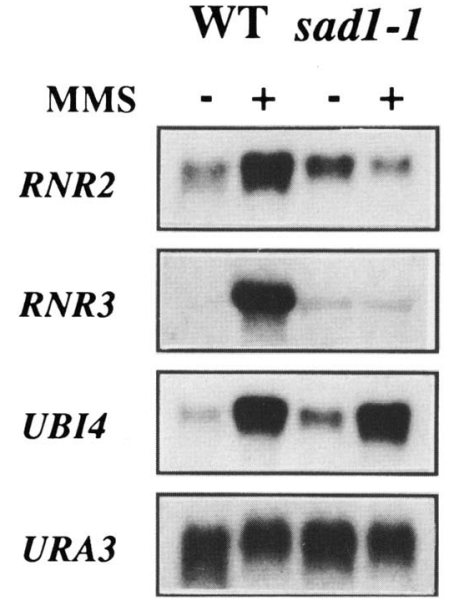

Figure 3. sad1-1 is defective for DNA damage inducibility of $R N R 2$ and $R N R 3$. Cultures at $\mathrm{OD}_{600}$ of 0.05 in YPD were treated with or without $0.1 \%$ MMS for $l \mathrm{hr}$ at $30^{\circ} \mathrm{C}$. RNA was extracted, fractionated on a formaldehyde-1\% agarose gel, transferred to nitrocellulose, and probed with ${ }^{32} \mathrm{P}$-labeled DNA probes derived from $R N R 2, R N R 3, U B I 4$, and $U R A 3$ as described in Materials and methods.

that $S A D 1$ is upstream of DUN1 and regulates its activity in response to DNA damage. To test this hypothesis, DNA damage-induced activation of Dunl was assayed in sad1 mutant strains. Wild-type cells treated with either HU or MMS exhibit slower migrating forms of Dunl (Fig. 4A). Neither treatment in sad1 mutants resulted in the Dunl mobility shift observed in wild-type cells, indicating that activation of Dun1 by DNA damaging agents is SAD1-dependent.

To further investigate the relationship between $S A D 1$ and $D U N 1$, the DNA damage-induced hyperphosphorylation of Dunl in vivo was examined in wild-type and sad1 mutant cells. As shown in Figure 4B, MMS treatment of wild-type cells overexpressing Dunl results in an increase of the phosphorylation state of Dun1. However, this response is absent in sad1 mutants, further strengthening the correlation of the mobility shift and autophosphorylation in response to DNA damage. These results suggest further that $S A D 1$ functions upstream of DUN1 in the signaling pathway that activates DNA damage-induced transcription.

\section{Cloning and disruption of SAD1}

A wild-type $S A D 1$ genomic clone was isolated by complementation of sad1-1 HU sensitivity and sequenced. This clone complements all of the checkpoint and transcriptional defects of the sad1-1 mutant (data not shown|. A GenBank data base search revealed that the open reading frame encodes a previously cloned gene, $S P K 1$, a serine/threonine protein kinase. SPK1 was isolated in a screen to identify yeast protein kinases (Stern et al. 1991) using anti-phosphotyrosine antibodies, and was shown to possess kinase activity in vitro. Futher- 

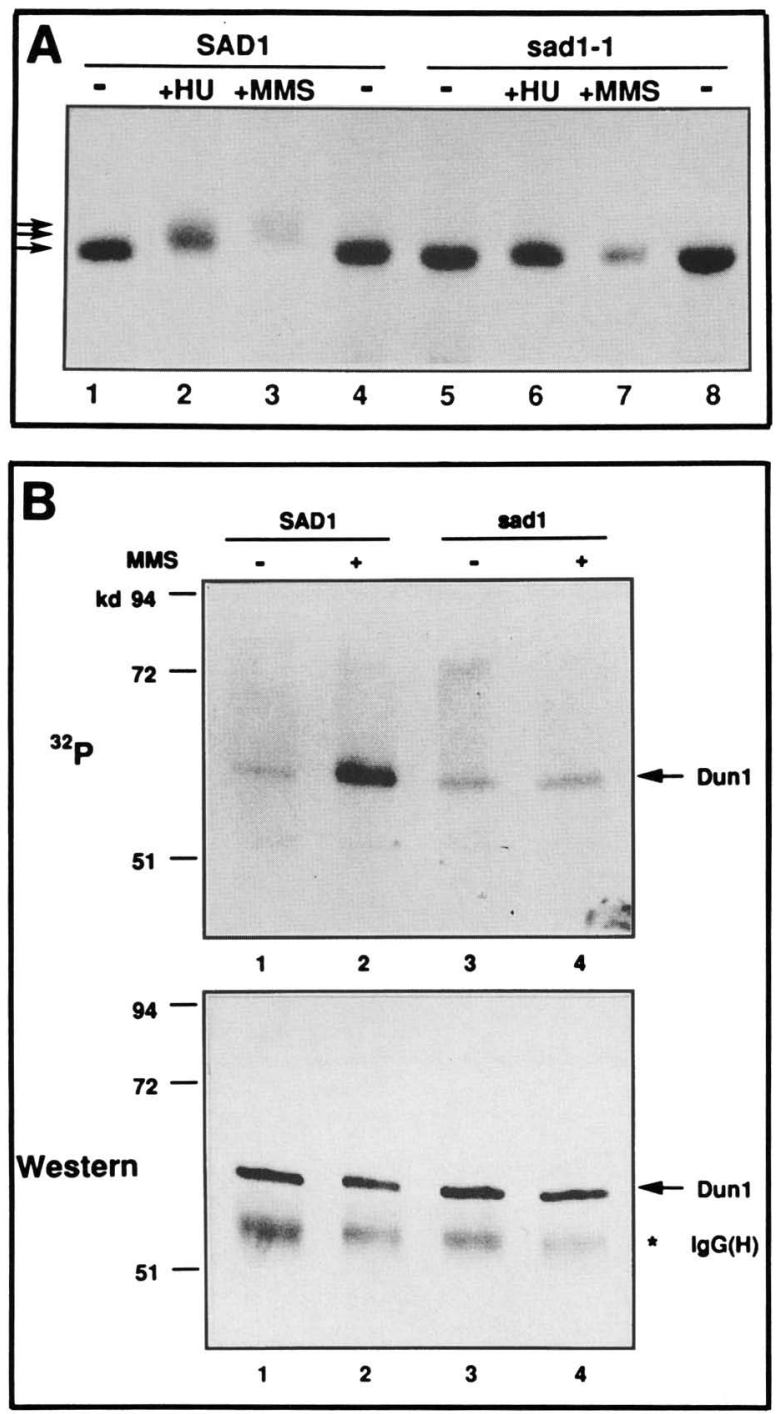

Figure 4. Dunl is not activated by DNA damage or replication blocks in sad1-1 mutants. (A) DNA damage-induced slow-migrating forms of Dunl are not generated in sad1-1 mutants. Wild-type (Y300) and sad1-1 (Y301) strains were grown in YPD to mid-log phase at $30^{\circ} \mathrm{C}$ and cultured for $3 \mathrm{hr}$ in the presence or absence of $150 \mathrm{mM} \mathrm{HU}$ or $0.1 \%$ MMS. Endogenous Dun 1 was immunoprecipitated, and in vitro kinase assays were performed. Kinase reaction products were fractionated on $8 \%$ SDSpolyacrylamide gels and subjected to autoradiography. Dun 1 from DNA-damaged wild-type cells migrates more slowly than that from undamaged cells. The production of slower migrating forms of Dun1 by DNA damage is abolished in a sad1-1 genetic background. Arrows indicate slow- and fast- migrating forms of Dun1. (B) MMS-induced hyperphosphorylation of Dunl is absent in sad1-1 mutants. Wild-type (Y300) and sad1-1 (Y301) strains containing a plasmid, pZZ74 (Zhou and Elledge 1993) that overproduce Dunl under control of the $G A P$ promoter were grown in YPD to mid-log phase and labeled with $\left[{ }^{32} \mathrm{PJH}_{3} \mathrm{PO}_{4}\right.$ for $2 \mathrm{hr}$ at $30^{\circ} \mathrm{C}$ in the presence or absence of $0.1 \%$ MMS. Dunl was immunoprecipitated from protein extracts, fractionated by SDS-PAGE, and transferred to nitrocellulose. Autoradiography was performed to determine the phosphorylation status of Dunl, and the filter was immunoblotted with anti-Dunl to show that equal amounts of Dunl were precipitated in each sample. more, Spk1 was shown to be nuclearly localized and to display cell cycle-regulated transcription (Zheng et al. 19931.

A null allele for $S A D 1$ was generated (Fig. 5A) and used to create a diploid heterozygous for $S A D 1$. Sporulation of the $S A D 1 / \Delta$ sad1::HIS3 heterozygous diploid revealed that $S A D 1$ is essential for cell viability (see Materials and methods) as has also been observed for SPK1 (Zheng et al. 1993). Inclusion of $S A D 1$ on a centromeric URA3 plasmid allows recovery of haploids with chromosomal sad1::HIS3 alleles. These strains were unable to grow in the absence of the plasmid as evidenced by lethality on media containing 5-fluoro-orotic acid (5-FOA) (data not shown), demonstrating further that $S A D 1$ is essential for mitotic viability.

Identification of $S A D 1$ as a protein kinase suggests that protein phosphorylation is important for checkpoint function and for coupling $S$ phase and mitosis. To test this hypothesis, a mutant allele in which a conserved lysine in the ATP-binding site is changed to an alanine was constructed, sad1-11 (K227A), and transformed into sad1-1 and $\Delta s a d 1:: H I S 3$ null mutants. The identical mutation in the Dunl kinase was found to diminish its kinase activity severely without affecting its stability (Zhou and Elledge 1993). sad1-11 (K227A) fails to complement the HU sensitivity of sad1-1 (Fig. 5B) or lethality of the $\Delta s a d 1:: H I S 3$ mutation (Fig. $5 \mathrm{C}$ ) using a plasmid shuffle assay, suggesting that Sadl kinase activity is required for both the cell cycle checkpoint and essential functions.

\section{cks1 Mutants suppress the HU sensitivity of sadl}

The mechanism through which the DNA damage and S-phase checkpoint pathways inhibit cell cycle progression is not known. An attractive target for inhibition of the $G_{1} / S$ and $G_{2} / M$ cell cycle transitions is the p34 ${ }^{C D C 28}$ protein kinase, as both transitions are regulated by $\mathrm{p} 34$ as well as the SAD1-dependent checkpoints. There is evidence to suggest that HU treatment of fission yeast cells results in persistent inhibitory phosphorylation of Tyr-15 on p34 ${ }^{c d c 2}$. However, mutational inhibition of tyrosine phosphorylation on $\mathrm{p} 34^{C D C 28}$ has no effect on the budding yeast S-phase checkpoint, and double mutant combinations of $c d c 28$ :Y19F and sad1-1 do not exacerbate sad1-1 HU lethality (data not shown). An equally likely target is CKS1 (Hadwiger et al. 1989), the budding yeast homolog of $S$. pombe suc1 ${ }^{+}$. p $13^{\text {suc1 }}$ binds p34/cyclin complexes and has the ability to alter the substrate specificity of p34 ${ }^{c d c 2}$ (Kusubata et al. 1992). CKS1 is also required for both the $\mathrm{G}_{1} / \mathrm{S}$ and $\mathrm{G}_{2} / \mathrm{M}$ transitions (Tang and Reed 1993) and is found associated with p34 ${ }^{C D C 28}$ in HU-treated cells (Stueland et al. 1993). Although the biochemical significance of $\mathrm{p} 18^{C K S 1}$ binding to $\mathrm{p} 34^{C D C 28}$ is not clear, a possible mechanism for $S A D 1$-dependent inhibition of cell cycle progression is negative regulation of $C K S 1$. If this were the case, it might be possible to suppress the HU sensitivity of sad1-1 by a partial loss of CKS1 function. To test this possibility, sad1 cks1 double mutants were constructed 
Allen et al.

Figure 5. $S A D 1$ kinase activity is required to complement sad1-1 and $\Delta s a d 1$ mutants; and cks1 mutants can suppress the HU sensitivity of sad1-1. (A) Position of $S A D 1$ on chromosome XVI. Arrows indicate the direction of transcription. Restriction sites: (B) BamHI; (M) MluI; (S) Styl; (X) Xhol. The position of the replacement of the SAD1-coding sequences with the HIS3- $\mathrm{Km}^{\mathrm{x}}$ cassette is indicated. Also shown is the position of the K227A site-directed mutation. $(B)$ Yeast strains were streaked upon an SC-uracil plate containing $18 \mathrm{~mm} \mathrm{HU}$ and incubated at $23^{\circ} \mathrm{C}$. From the top quadrant and clockwise: (Y303) sad1-1 CKS1 + pJA92 (SAD1); (Y302) sad1-1 CKS1+pUN70; (Y314) SAD1 cks1-ts38+pUN70; (Y316) sad1-1 cks1-ts38+ pUN70; (Y317) sad1-1 cks1ts38+ pIA103 (CKS1); and (Y304) sad1-1 CKS1 + pJA107 (sad1-11 K227A). All strains were grown on SC-uracil in the absence of $\mathrm{HU}$ (data not shown). (C) To test for complementation of the sad1::HIS3 deletion, a plasmid shuffle assay was employed using Y324 [ura3-1 trp1-1 Asad1::HIS3 + pJA92 (URA3, SAD1)). Y324 containing pUN40 (TRP1), pJA121 (SAD1 TRP1), or pJA101 (TRP1 sad1-11) and Y300 containing pUN40 (TRP1) were streaked onto SC plates containing 5-FOA and incubated at $30^{\circ} \mathrm{C}$. Only cells capable of growing in the absence of
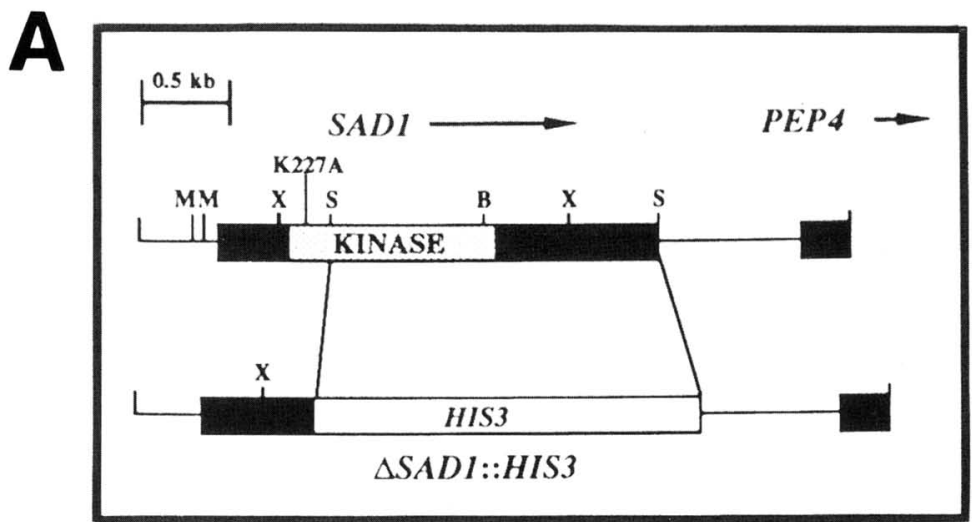

뭉
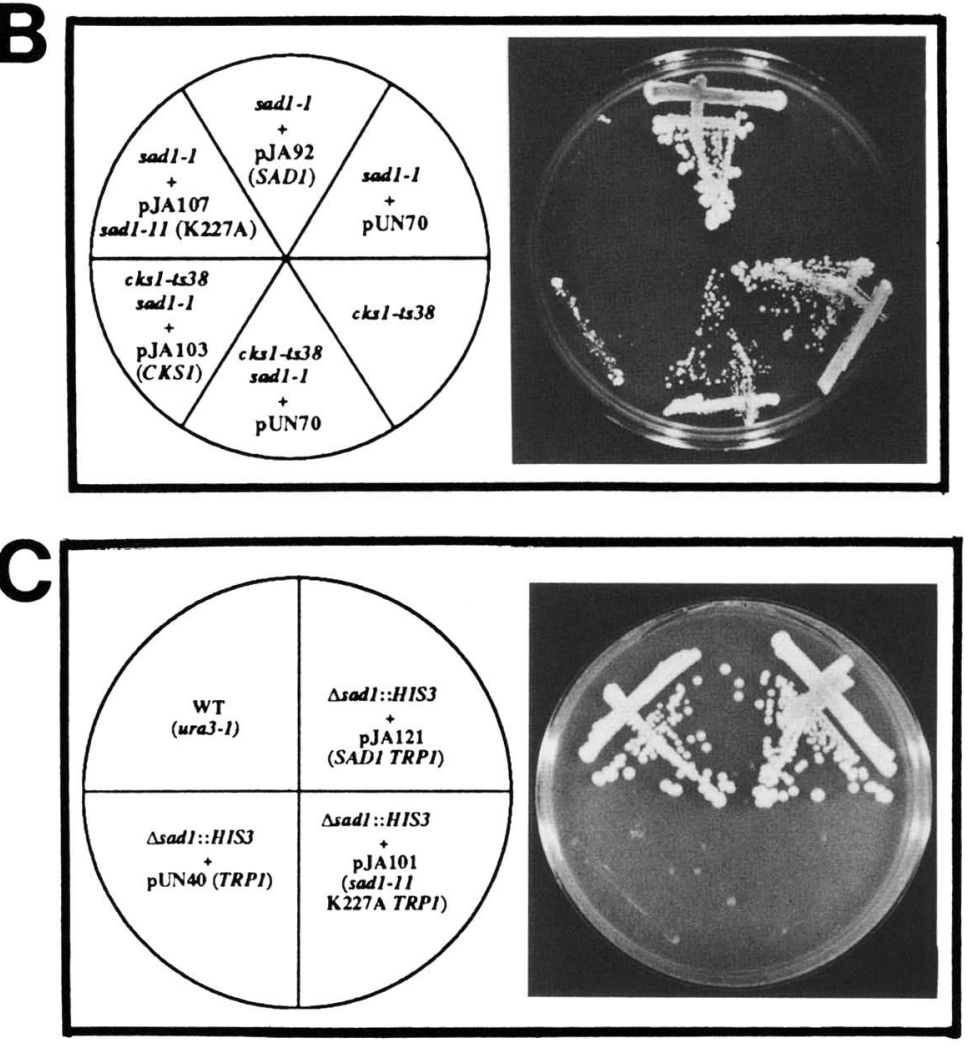

and assayed for growth on HU. As shown in Figure 5B, the $c k s$-ts 38 temperature-sensitive allele suppresses the HU-sensitivity of sad1-1. Suppression of sad1-1 is attributable to the presence of the cks1-ts 38 mutation, because a plasmid-borne copy of wild-type CKS1 abolishes the ability of the double mutant to grow. This result suggests that the $S A D 1$-dependent checkpoint pathway might inhibit cell cycle progression through negative regulation of $C K S 1$. Alternatively, cks1 mutants may suppress sad1 through nonspecific elongation of a critical cell cycle transition. Regardless of the involvement of $C K S 1$ in checkpoint function, these experiments provide further evidence supporting the notion that it is inappropriate cell cycle progession that leads to death in sad1 mutants.

\section{Overproduction of SAD1 can suppress the UV} sensitivity of rad 9 mutants

sad1 and rad9 mutants are both unable to arrest the cell cycle in $G_{1}$ or $G_{2}$ in response to DNA damage. It is possible that they are components in a common genetic pathway. To investigate this relationship further, we examined the effects of $S A D 1$ overproduction on UV sensitivity in a rad 9 mutant. If $R A D 9$ acts downstream of $S A D 1$ in a linear genetic pathway, then overexpression of $S A D 1$ in a rad9 null mutant should have no effect on the rad9 phenotype. However, overproduction of $S A D 1$ from the inducible $G A L$ promoter strongly suppresses the UV sensitivity of rad9 mutants (Fig. 6). This result suggests that it is unlikely that $R A D 9$ is downstream of 


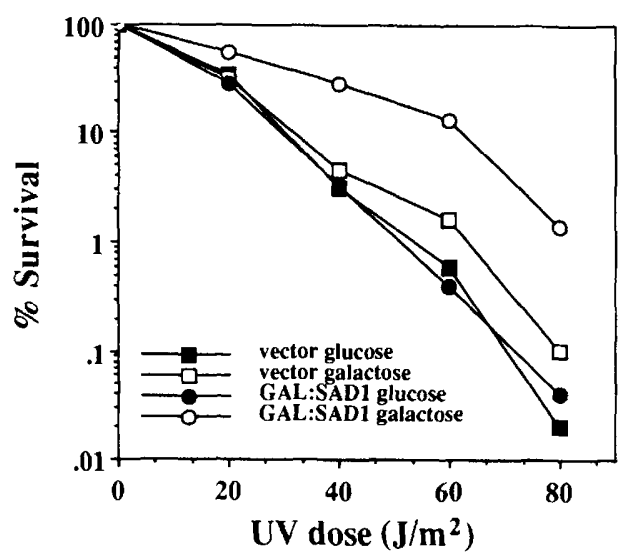

Figure 6. Overexpression of $S A D 1$ suppresses the UV sensitivity of rad9 mutants. Y318 (rad9::LEU2), containing pUN70 (URA3, $\mathbf{0}, \square)$, or pJA98 (URA3 GAL:SAD1, O, O), were grown to log phase in SC-uracil media containing either glucose $\mid \square$, O), or galactose $\{\square, O\}$ as a carbon source. Dilutions were plated onto SC-uracil medium containing the appropriate carbon source and were UV-irradiated at the indicated doses. After 3-4 days growth at $30^{\circ} \mathrm{C}$, colony-forming units were counted.

SAD1 in a linear pathway, although alternative interpretations of this experiment exist and are discussed below.

\section{Discussion}

Inhibition of DNA synthesis results in cell cycle arrest prior to mitosis through the action of a cell cycle checkpoint. A genetic screen coupled with an analysis of preexisting rad mutants has identified $S A D$ genes controlling this checkpoint. Some of these sad and rad mutants allow yeast cells to continue cell cycle progression in the presence of the DNA synthesis inhibitor HU. We have focused on $S A D 1$, an essential gene that we found to encode a protein kinase. sad1 and sad 3 (data not shown) mutants are defective in the $S$-phase checkpoint, as well as the $G_{1}$ and $G_{2}$ DNA damage checkpoints. In addition, sad1 mutants are also defective for transcriptional activation of DNA damage-inducible genes. During the course of this work, sad1 was also isolated independently as mec2 in a screen for checkpoint mutants showing synthetic lethality with $c d c 13$ mutations (Weinert et al. 1994). As mentioned in the introductory section, mec2 mutants were found to display properties consistent with a role in the S-phase and $G_{2}$ checkpoints and were shown to be sensitive to a variety of DNA damaging treatments.

\section{SAD1-dependent cell cycle arrest}

$S A D 1$ controls the $\mathrm{G}_{1}, \mathrm{G}_{2}$, and $\mathrm{S}$-phase checkpoints. The S-phase and $G_{2}$ checkpoints may actually represent the same arrest point in the cell cycle, but $G_{1}$ is clearly distinct. The fact that all three checkpoints are controlled by a single gene suggests a common mechanism of cell cycle arrest at these different points. Because $S A D 1$ controls both $G_{1}$ and $G_{2}$ checkpoints, it is possible that the
Sadl target also has a role during both transitions. It is well established that both the $G_{1} / S$ and the $G_{2} / M$ transitions in budding yeast are controlled by the p34 ${ }^{C D C 28}$ protein kinase, associated cyclin regulatory subunits, and the CKS1 gene, a Cdk-binding protein of unknown biochemical function. The observation that cks1-ts 38 suppresses the HU sensitivity of sad1-1 suggests a possible role for CKS1 in SAD1-dependent checkpoints. Sadl could negatively regulate $\mathrm{Cksl}$ and prevent its transition-promoting activity. To this end, it will be of interest to determine whether Cksl association with p34 ${ }^{C D C 28}$ is cell cycle or DNA damage regulated as well as whether Sadl can phosphorylate Cks1 in vitro. However, it is equally plausible that hypomorphic alleles of CKS1 suppress sad1 by providing a synthetic delay at key cell cycle transitions. If CKS1 is not involved in the $S A D 1$-dependent checkpoint, it must define the existence of an independent checkpoint because sad1 mutants do not alter its $c d c$ phenotype. Furthermore, the CKS1 checkpoint is distinct from the checkpoint activated by nocodozole because nocodazole treatment cannot suppress sad1.

Cyclins are another possible inhibitory target. Cyclin overexpression fails to show checkpoint deficiencies (Stueland et al. 1993), although other aspects of cyclin function have not been explored and remain as potential effectors. An alternative explanation is the existence of a control system that can alter $\mathrm{p} 34^{C D C 28}$ activity in a manner independent of tyrosine phosphorylation, such as by synthesis of a Cdk inhibitor analogous to the mammalian CIP1 gene, an inhibitor of cyclin-dependent kinases. However, yeast homologs have not yet been identified. Finally, it is also possible that $S A D 1$ delays the cell cycle in a p34-independent manner, perhaps through negative regulation of an unidentified cell cycle regulator such as the NimA kinase in Aspergillus (Osmani et al. 1988). Identification of in vivo Sad1 substrates will be a critical step toward understanding how this cell cycle arrest is mediated.

\section{Nature of HU-induced lethality}

sad1 mutants commit to inviability soon after entering $\mathrm{S}$ phase in the presence of HU. A similar observation has been reported recently for a class of mutants in $S$. pombe (Enoch et al. 1992), and it has been suggested that these mutants are defective for recovery from S-phase arrest in addition to being deficient in the S-phase feedback control. We have examined DNA synthesis in sad1 cells released from an $\alpha$-factor block into $\mathrm{HU}$ and nocodazole for $30 \mathrm{~min}$ and then placed into nocodazole alone and have observed no difference between wild-type and sad1 cells by FACS (J. Allen and S. Elledge, unpubl.). This suggests that the majority of DNA synthesis can resume after HU arrest. Whereas sad1 mutants may also be defective for some aspect of S-phase arrest recovery, an alternative explanation is that following release from $G_{1}$ in the presence of $\mathrm{HU}$, sad1 cells become prematurely and irreversibly committed to a series of biochemical reactions that result in initiation of mitosis. Although 
segregation of unreplicated chromosomes would certainly be lethal, it is unlikely to be the sole explanation of lethality in these cells because nocodazole, which blocks anaphase, is unable to suppress killing when present during and after $\mathrm{HU}$ treatment (data not shown). This is based on the assumption that cells are still competent to replicate DNA at the nocodazole block, which has not been tested. Thus, the nature of HU-induced lethality is not clear but may result from other aspects of premature mitotic commitment such as chromosome condensation, maturation of kinetechores, or alterations in nuclear architecture.

\section{Does SAD1 coordinate $S$ phase and mitosis in a normal} cell cycle?

The S-phase and DNA damage checkpoints allow cells to integrate cell cycle progression with the replicational status and integrity of the genome. However, it is not known whether these checkpoints also order events in a normal cell cycle in the absence of DNA damage or replication blocks, or whether S-phase and mitotic coordination is normally ensured by relative timing. The interpretation of an active mitotic inhibitory signal produced from S-phase nuclei is supported by the experiments of Rao and Johnson (1970), who observed that fusion of unperturbed mammalian S-phase cells to $G_{2}$ cells caused the $G_{2}$ nucleus to arrest entry into mitosis until the S-phase nucleus completed DNA replication. The data presented here do not provide a definitive answer for yeast, although several properties of sad1 mutants are germane to this issue. First, SAD1 is a member of the MluI cell cycle box (MCB) group of cell cycleregulated genes expressed in $\mathrm{S}$ phase that encode many enzymes essential for $S$ phase (Zheng et al. 1993; J. Allen and S. Elledge, unpubl.). Second, unlike RAD9, SAD1 is essential for viability, suggesting a role in every cell cycle. It is likely that this essential function is during $S$ phase, although $S A D 1$ could be essential for reasons unrelated to feedback control. Finally, sad1 mutants accelerate mitotic entry in the presence of HU, although not significantly faster than wild-type cells. It is difficult to imagine why a treatment that normally blocks cell cycle progression would have the opposite effect in a sad1 mutant. Perhaps the signal to inhibit mitosis emanates from active replication forks that are diminished in the presence of HU. Normally, a dampened but persistant signal would be sufficient to activate the checkpoint, but in a sad1-1 mutant the reduced signal and diminished transducer together would be insufficient and cells would commit to mitosis faster. Without a conditional lethal allele of $S A D 1$, it is not possible to determine definitively whether Sadl controls normal timing of mitosis.

\section{SAD1 controls the cell cycle arrest response to DNA damage}

sad1 mutants are defective for the RAD9-dependent $\mathrm{G}_{1}$ and $\mathrm{G}_{2}$ DNA damage checkpoints. If $R A D 9$ functions downstream of $S A D 1$, then overexpression of $S A D 1$ in a
$\Delta r a d 9$ background should have no effect with respect to the damage sensitivity of $\Delta r a d 9$ mutants. However, overexpression of $S A D 1$ partially suppresses the UV sensitivity of $\triangle \mathrm{rad} 9$ strains. If $S A D 1$ overproduction enhances its role in checkpoint-mediated cell cycle arrest, then $R A D 9$ cannot function after $S A D 1$ in a linear pathway. However, overexpression of $S A D 1$ slightly slows down the cell cycle in wild-type cells. If this slow growth is not a manifestation of the checkpoint function of $S A D 1$, suppression of rad 9 mutants may be attributable to nonspecifically lengthening the cycle. Because we cannot distinguish between these alternatives, we cannot definitively order $S A D 1$ and $R A D 9$.

\section{SADl controls the transcriptional response to DNA damage}

In addition to multiple checkpoint deficiencies, sad1 mutants also exhibit a DNA damage-uninducible phenotype similar to that of the dun mutants (Zhou and Elledge 1993|, defective for RNR2 and RNR3 induction but proficient for $U B I 4$ induction. Mutants in DUN1, a protein kinase whose activity is increased in response to DNA damage, are proficient in their cell cycle response to DNA damage and have only a subset of sad1 phenotypes, suggesting that $D U N 1$ is downstream of $S A D 1$. In addition, Dunl is not activated in sad1 mutants. Based on these observations coupled with the DNA damage checkpoint role, it is likely that the Sadl kinase is positioned very close to the signal sensor in the DNA damage signaling pathway.

The relationship between the checkpoint and transcriptional roles of $S A D 1$ is not clear. The absence of RNR3 expression during a normal $\mathrm{S}$ phase in which $S A D 1$ is likely to function presents a puzzle. If Sad1 is functioning during a normal $S$ phase to activate the checkpoint, why does it not also activate expression of RNR3 at that time? The presence of DNA damage or a replication block must provide information distinct from normal DNA replication to $S A D 1$ or its effectors. Sad 1 does contain potential regulatory domains on either side of the kinase domain that could respond to or send different signals. Activation of $R N R 3$ transcription could require higher levels of Sadl function than is necessary to activate the checkpoint. Alternatively, the activation of a checkpoint might lengthen the period of the cell cycle during which a factor accumulates that facilitates transcriptional activation. This factor could be active $S A D 1$ or a substrate. Another possibility is that a SAD1independent pathway is additionally required to provide DNA damage information necessary for RNR3 induction. These complexities can only be resolved by rigorous biochemical and genetic analysis of the $S A D 1 \mathrm{ki}-$ nase.

A model depicting the genetic pathway regulated by Sadl is shown in Figure 7. SAD1 is placed downstream from the direct sensors for DNA damage and DNA replication blocks. Although no formal evidence has been presented that Sadl is regulated in response to these stimuli, the fact that Sadl is a protein kinase makes it 


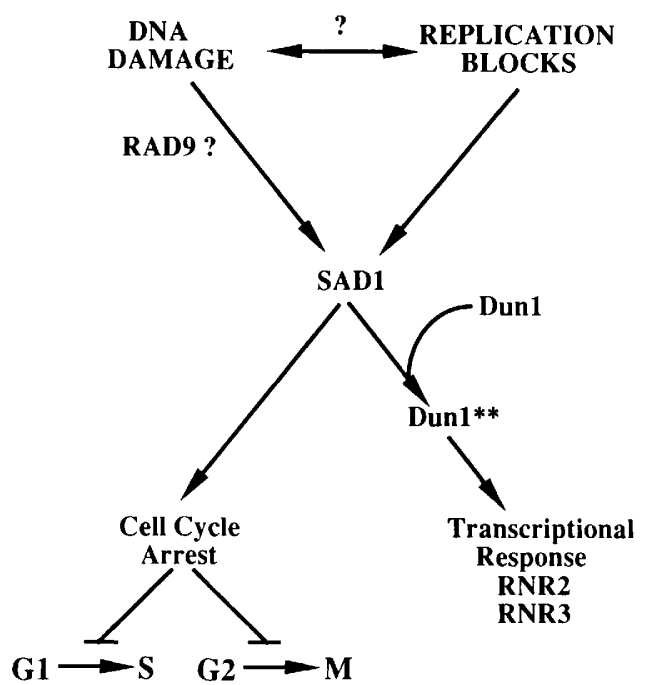

Figure 7. A model for the role of $S A D 1$ in cell cycle control and the cellular response to DNA damage. $S A D 1$ is required to delay the cell cycle in response to DNA damage in $G_{1}$ and $G_{2}$ and for arrest induced by replication blocks. An arrow is placed between DNA damage and replication blocks, as some agents are likely to activate both pathways. $R A D 9$ is tentatively placed upstream of $S A D 1$. Although shown schematically, it is not clear whether $S A D 1$ arrests the cell cycle in response to replication blocks by the same mechanism that $S A D 1$ prevents mitosis in response to DNA damage at $\mathrm{G}_{2} / \mathrm{M}$. $S A D 1$ is also required for the DNA damage-induced expression of RNR2 and $R N R 3$. Dunl is placed downstream of $S A D 1$ because Dunl kinase activity is not activated in response to DNA damage in sad1-1 mutants.

highly likely that it will function as a signal transducer. An arrow is placed between DNA damage and replication blocks because some agents may activate both pathways. DUN1 is placed downstream of SAD1 because $S A D 1$ is necessary for activation of Dunl kinase activity in response to DNA damage and replication blocks. This epistatic relationship suggests the possibility that Dun1 may be a direct substrate for the Sadl kinase. Because Dunl has intact cell cycle checkpoints, a separate branch leads from $S A D 1$ to the cell cycle arrest. It should be noted that although Dunl mutants are not checkpoint defective, Dunl may play a redundant role in the checkpoint pathway. RAD9 is placed upstream of $S A D 1$ because of the suppression data, although as mentioned earlier, this positioning is tentative.

A number of experiments in fission yeast have suggested that active replication is necessary to prevent mitotic entry. $c d c 18$ and cut 5 mutants fail to initiate DNA replication and allow cells to enter mitosis with a $G_{1}$ content of DNA (Kelly et al. 1993; Saka and Yanagida 1993). If they are allowed to first enter S phase before a shift to the nonpermissive temperature, they must finish replication before mitosis can begin. Thus, active replication is implicated in checkpoint function. These mutants are unlike sad1 mutants in that they are not HU sensitive. An alternative model for Sadl function might be in maintaining the integrity of the replication com- plexes needed for signaling during disruptive events that might promote complex disassembly. Complex dissassembly would signal S-phase completion. In this model, $S A D 1$ would play an indirect role in checkpoint function. Current information cannot distinguish between these models. The model that Sadl is a direct transducer of the checkpoint signal predicts that Sad1 activity will vary in response to checkpoint activating signal. Analysis of Sadl kinase activity regulation in response to DNA damage or isolation of constitutive cell cycle arrest mutants of SAD1 would facilitate resolution of these issues.

\section{Feedback controls and cancer}

The consequences of checkpoint control deficiency in unicellular organisms include chromosome loss, genetic instability, and cell death. There is an accumulating body of evidence that suggests that lesions in feedback controls, such as p53 and AT, play a pivotal role in tumorigenesis in mammals. It is probable that checkpoint control mechanisms will be conserved throughout evolution as is the basic cell cycle regulatory machinery and that further molecular analysis of the $S A D$ and $R A D$ genes will provide a general framework for understanding feedback controls and checkpoint function in all eukaryotes.

\section{Materials and methods}

Yeast strains, genetic procedures, and growth conditions

Yeast strains used in this study are listed in Table 2. Standard yeast genetic procedures were used (Rose et al. 1990). Yeast cultures were grown in YPD ( $1 \%$ yeast extract, $2 \%$ Bacto-peptone, supplemented with $2 \%$ glucose or galactose, as indicated). Synthetic complete (SC) medium is minimal medium containing various amino acids as described (Sherman et al. 1979) and was used when plasmid selection was required. Yeast transformation was performed by the lithium acetate procedure (Ito et al. 1983). The DNA synthesis inhibitor HU (Sigma) was added to media at $0.2 \mathrm{M}$ unless stated otherwise. Benomyl, which hydrolyzes in solution to the microtubule inhibitor methyl benzimidazole-2-yl-carbamate, was supplied by DuPont. $\mathrm{G}_{1}$ cell cycle arrest was achieved by incubating log-phase cultures grown in YPD ( $\mathrm{pH} 3.9$ ) with $5 \mu \mathrm{g} / \mathrm{ml}$ of $\alpha$-factor (Peninsula Laboratories) for $1 \mathrm{hr}$ at $30^{\circ} \mathrm{C}$ and subsequent addition of $5 \mu \mathrm{g} / \mathrm{ml}$ of $\alpha$-factor for $1 \mathrm{hr}$ prior to release. Yeast strains were grown at $30^{\circ} \mathrm{C}$ unless stated otherwise. Killing curves for $\mathrm{HU}$ and UV treatment were performed in duplicate, and the average of two points is shown.

\section{Staining of cells for microscopy and flow cytometry}

Cells were fixed by the addition of $3.7 \%$ formaldehyde to growing cultures that were incubated at $30^{\circ} \mathrm{C}$ for $1 \mathrm{hr}$. Cells were washed twice in phosphate-buffered saline (PBS) and resuspended in PBS +1.2 M sorbitol. Cells were stained for DNA with $1 \mu \mathrm{g} / \mathrm{ml}$ of DAPI, and microtubules were visualized with the antitubulin monoclonal antibody YOL1/34 and a FITC-conjugated secondary antibody as described (Kilmartin and Adams 1984). To categorize cellular morphologies, 200 cells were scored for each time point. To measure DNA content, cells were fixed with $70 \%$ ethanol and stained with propidium iodide as 
Allen et al.

Table 2. Strain list

\begin{tabular}{|c|c|c|}
\hline Name & Relevant genotypes & Source \\
\hline Y300 & MATa; can1-100; ade2-1; his3-11,15; leu2-3,112; trp1-1; ura3-1 & this study \\
\hline Y301 & MATa; sad1-1; can1-100; ade2-1; his3-11,15; leu2-3,112; trp1-1; ura3-1 & this study \\
\hline Y302 & Y301 + pUN70 (URA3) & this study \\
\hline Y303 & $\mathrm{Y} 301+\mathrm{p}$ )A92 (URA3 SAD1) & this study \\
\hline Y304 & $\mathrm{Y} 301+$ pJA107 (URA3 sad1-11 K227A) & this study \\
\hline Y305 & MATa; sad2-1; can1-100; ade2-1; his3-11,15; leu2-3,112; trp1-1; ura3-1 & this study \\
\hline Y306 & MATa; sad3-1; can1-100; ade2-1; his3-11,15; leu2-3,112; trp1-1; ura3-1 & this study \\
\hline Y307 & MATa; sad4-1; can1-100; ade2-1; his3-11,15; leu2-3,112; trp1-1; ura3-1 & this study \\
\hline Y308 & MATa; sad5-1; can1-100; ade2-1; his3-11,15; leu2-3,112; trp1-1; ura3-1 & this study \\
\hline Y309 & $M A T \alpha ; c d c 9-1 ;$ his $7-1 ;$ ura1-1 & this study \\
\hline Y310 & $M A T \mathbf{a} ; c d c 9-1 ; \operatorname{sad} 1-1$ & this study \\
\hline Y311 & MATa; cdc9-1; sad1-1; ade2-1 & this study \\
\hline Y312 & $\begin{array}{l}\text { MATa/ } \alpha ; \text { SAD1/sad1::HIS3; can1-100/can1-100; ade2-1/ade2-1; his3-11,15/his3-11,15; } \\
\text { leu2-3,112/leu2-3,112; trp1-1/trp1-1; ura3-1/ura3-1 }\end{array}$ & this study \\
\hline Y313 & MATa; cks1::LEU2; ade1; his2; leu2-3,112; trp1-1; + pCKS1 (TRP1 CKS1) & Tang and Reed (1993) \\
\hline Y314 & MATa; cks1::LEU2; ade1; his2; leu2-3,112; trp1-1; + pcks1-ts38 (TRP1 cks1-ts38) & Tang and Reed (1993) \\
\hline Y315 & MATa; sad1-1; cks1::LEU2; leu2-3,112; trp1-1; + pcks1-ts38 (TRP1 cks1-ts38) & this study \\
\hline Y316 & $\mathrm{Y} 315+$ pUN70 (URA3) & this study \\
\hline Y317 & $\mathrm{Y} 315+$ pIA103 (URA3 CKS1) & this study \\
\hline Y318 & MAT $\alpha$, rad9::LEU2; ade2-1; his3-11,15; leu2-3,112; trp1-1; ura3-1 & this study \\
\hline Y319 & $\mathrm{Y} 318+$ pUN70 (URA3) & this study \\
\hline Y320 & $\mathrm{Y} 318+$ pJA98 (URA3 GAL-SAD1) & this study \\
\hline Y321 & $\mathrm{Y} 300+\mathrm{pUN} 70(U R A 3)$ & this study \\
\hline Y322 & Y300 + pJA98 (URA3 GAL-SAD1) & this study \\
\hline Y323 & $\begin{array}{l}\text { MATa/ } \alpha ; \text { can1-100/can1-100; ade2-1/ade2-1; his3-11,15/his3-11,15; leu2-3,112/leu2-3,112; } \\
\quad \operatorname{trp1-1/trp1-1;~ura3-1/ura3-1~}\end{array}$ & this study \\
\hline Y324 & $\begin{array}{l}\text { MATa; can1-100; ade2-1; his3-11,15; leu2-3,112; trp1-1; ura3-1 } \Delta \text { sad1::HIS3 + pJA92 } \\
\quad \text { (URA3, SAD1) }\end{array}$ & this study \\
\hline
\end{tabular}

described (Hutter and Eipel 1979). The DNA content of at least 10,000 cells was determined for each sample with an EPICS model 753 Laser System.

\section{sad mutant isolation}

Y300 was mutagenized with ethyl methanesulfonate to $20 \%$ survival and plated on YPD plates at $30^{\circ} \mathrm{C}$. Mutagenized colonies were replica-plated to YPD plates, and YPD plates containing $100 \mathrm{mM} \mathrm{HU}$ and $\sim 700 \mathrm{HU}$-sensitive strains were isolated. HU-sensitive mutants were assayed for HU reversibility by replica-plating to YPD plates containing $200 \mathrm{mM} \mathrm{HU}$, incubation for $12 \mathrm{hr}$ at $30^{\circ} \mathrm{C}$, and replica-plating back to YPD plates. Fortyfive strains that failed to recover were chosen for further study. These were assayed further for $\mathrm{HU}$ reversibility by treating logphase cultures in YPD with $200 \mathrm{~mm} \mathrm{HU}$ for $6 \mathrm{hr}$ at $30^{\circ} \mathrm{C}$. Aliqouts were removed at 2 -hr intervals, and dilutions were plated onto YPD plates and incubated at $30^{\circ} \mathrm{C}$ for $3-4$ days to determine percent survival. Nine mutants were isolated that showed a rapid loss of viability in the presence of HU. $\alpha$-Factor suppression of HU-induced lethality was tested by arresting mutant strains in $G_{1}$ with $\alpha$-factor prior to release into YPD that contained $200 \mathrm{~mm} \mathrm{HU}$ or media containing $\alpha$-factor and HU. At 2-hr intervals, dilutions were plated on YPD plates to determine percent survival, and $2 \mu \mathrm{g} / \mathrm{ml}$ of $\alpha$-factor was added to $\alpha$-factortreated samples. Six sad mutants representing five complementation groups were isolated that exhibit $\alpha$-factor-suppressible HU lethality. Mutants were backcrossed six times to nonmutagenized parental strains to rid the cell background of unlinked mutation arising during mutagenesis.

\section{Determination of DNA damage-induced cell cycle delay}

To measure $G_{1}$ arrest in response to DNA damage, log-phase cultures were synchronized in $G_{1}$ with $\alpha$-factor as described above, plated onto YPD plates, and UV-irradiated with $40 \mathrm{~J} / \mathrm{m}^{2}$. Cells were washed from plates, rinsed to remove pheromone, and resuspended in fresh YPD. At timed intervals, samples were removed for analysis of DNA content and determination of budding kinetics. Two hundred cells were scored for each sample.

Y310 and Y311 (cdc9-1 sad1-1) were derived by crossing Y301 and $\mathrm{Y} 309$. The presence of both mutations was verified by temperature sensitivity and failure to complement $c d c 9$ or sad1 strains and by complementation of $c d c 9-1$ sad1-1 HU sensitivity by pJA90 (SAD1). For reversibility analysis, wild-type (Y300), cdc9-1 (Y309), and cdc9-1 sad1-1 (Y310 and Y311) strains were grown to $\log$ phase at $23^{\circ} \mathrm{C}$ and shifted to $37^{\circ} \mathrm{C}$ for $4 \mathrm{hr}$. Samples were removed at timed intervals and dilutions were plated onto YPD plates at $23^{\circ} \mathrm{C}$. After 5 days growth, colony-forming units were counted to determine cell survival. $G_{2} / M$ DNA damageinduced cell cycle delay was also assayed by UV-irradiating benomyl-arrested cells and following the rate of nuclear division following benomyl release as described (Weinert and Hartwell 1993).

\section{DNA damage-induced transcription in sadl mutants}

$\mathrm{Y} 300$ and $\mathrm{Y} 301$ were grown in YPD to $\mathrm{OD}_{600}$ at 0.05 at $23^{\circ} \mathrm{C}$. Low temperature and density were used to maintain low UBI4 basal levels. Cultures were split into two, and experimental samples were treated with $0.1 \%$ MMS for $1 \mathrm{hr}$. Total RNA was prepared and subjected to Northern analysis. Probes corre- 
sponded to the $0.9-\mathrm{kb}$ HindIII fragment of RNR2 from pSE310, the $2.5-\mathrm{kb}$ MluI-HindIII fragment of RNR3 from pSE734, and the 2.2-kb EcoRI fragment of UBI4 from pUB200.

\section{Immunoprecipitations and kinase assays}

Ueast extract $(100 \mu \mathrm{g})$ was diluted in $500 \mu \mathrm{l}$ of DB buffer $(20 \mathrm{~mm}$ Tris- $\mathrm{HCl}$ at $\mathrm{pH} 7.9,100 \mathrm{~mm} \mathrm{NaCl}, 2 \mathrm{~mm}$ EDTA, $0.05 \%$ Tween $20,1 \mathrm{mM}$ PMSF, $0.1 \mu \mathrm{g} / \mathrm{ml}$ of leupeptin, $0.1 \mathrm{~mm}$ benzymidine, 1 $\mu \mathrm{M}$ aprotinin, $0.1 \mu \mathrm{g} / \mathrm{ml}$ of pepstatin, $0.1 \mathrm{mM} \mathrm{Na}_{3} \mathrm{VO}_{4}$, and 30 $\mathrm{mM} \mathrm{NaF} /$ and incubated with $10-20 \mu \mathrm{l}$ of affinity-purified antiDunl antibodies for $1 \mathrm{hr}$ at $4^{\circ} \mathrm{C}$. Protein A-Sepharose CL-4B beads were used to precipitate immunocomplexes as described (Zhou and Elledge 1993). Immunocomplexes were incubated in $25 \mu \mathrm{l}$ of kinase buffer with $2 \mu \mathrm{M}$ cold ATP and $2.5 \mu \mathrm{Ci}$ of $\left[\gamma^{32} \mathrm{P}\right]$ ATP for $30 \mathrm{~min}$ at $30^{\circ} \mathrm{C}$. Reactions were terminated by the addition of $25 \mu \mathrm{l}$ of $2 \times$ SDS sample buffer. Phosphorylated products were visualized by $8 \%$ SDS-polyacrylamide gels and autoradiography.

\section{Determination of the in vivo phosphorylation state of Dun1}

$\mathrm{Y} 300$ and $\mathrm{Y} 301$ were grown to $\mathrm{OD}_{600}$ of 0.2 in $100 \mathrm{ml}$ of YPD, without inorganic phosphate (YPD- $\left.\mathrm{PO}_{4}\right)$ (Salah-ud-Din et al. 1990). Cells were pelleted, resuspended in $10 \mathrm{ml}$ of YPD-PO containing $1 \mathrm{mCi}$ of $\left[{ }^{32} \mathrm{P}\right] \mathrm{H}_{3} \mathrm{PO}_{4}$, and cultured for $2 \mathrm{hr}$ at $30^{\circ} \mathrm{C}$ in the presence or absence of $0.1 \%$ MMS. Protein extraction and immunoprecipitation of Dunl were performed as described above except that $100 \mu \mathrm{g}$ of RNase A was added to each immunoprecipitation reaction prior to electrophoresis. Samples were subjected to Western blot analysis and autoradiography.

\section{Cloning of SAD1}

A yeast genomic centromeric library carrying the URA3-selectable marker (Ramer et al. 1993) was transformed into sad1-1. $\mathrm{Ura}^{+}$transformants $\left(5 \times 10^{5}\right)$ were plated onto SC plates lacking uracil containing $100 \mathrm{mM}$ HU. Three plasmids, pIA90, pIA91, and pJA92, complemented sad1-1 upon retransformation and contained overlapping genomic inserts. A common 1.5-kb XhoI fragment was subcloned into pBS KSII + (Stratagene) and sequenced (Sanger et al. 1977). A null allele for SAD1 was generated by transplacement of the 3.9-kb HIS3-containing XhoI fragment from pIA100 into Y323 and selection for histidine prototrophy. Diploids (Y312) heterozygous for SAD1 were confirmed by Southern blotting. pJA93 (URA3 SAD1) rescues viability of $\mathrm{His}^{+}$haploids from tetrads. $\mathrm{His}^{+} \mathrm{Ura}^{+}$spores are also 5-FOA sensitive, demonstrating the requirement for wildtype $S A D 1$.

\section{Plasmid constructions}

The 4.2-kb XhoI partial fragment from pJA90 was subcloned into XhoI-digested pBS KSII + (Stratagene) to give pJA93. The $S A D 1$ open reading frame was amplified from pJA93 by polymerase chain reaction (PCR) with the $5^{\prime}$ primer, $5^{\prime}$ CAGGCATATGGAAAATATTACACAACCC-3', and the $3^{\prime}$ primer, 5'-TCTTAGCGGCCGCCCATGGGCGAAAATTGCAAATTCTCGGG-3'. NdeI and NotI sites are underlined, respectively. The PCR-derived product was digested with BgIII, and the resulting $2.0-\mathrm{kb}$ fragment representing the $3^{\prime}$ region of SADl was subcloned as a BgIII blunt-ended fragment into BgIIISmaI-digested pSE386 to give pJA95.

To place $S A D 1$ under T7 control, a three-way ligation was performed using the $0.5-\mathrm{kb}$ fragment from the NdeI-BglII-digested SAD1 PCR-derived product described above, the $3.2-\mathrm{kb}$
BglII-NotI fragment from pJA95, and the NdeI-NotI-digested pETHAX vector to give pIA97. The PCR-derived fragment was sequenced after cloning and was not mutant. To place $S A D 1$ under control of the $G A L$ promoter on a $C E N$ plasmid, the 2.7kb NcoI(blunt)-NotI fragment from pJA97 was cloned into Xbal(blunt)-NotI-digested pSE556 to give pIA98.

A transplacement vector, plA100, containing a $S A D 1$ null allele was constructed by replacing the $1.7-\mathrm{kb}$ StyI fragment of pJA93 with the 2.3-kb Smal fragment from pJA50 (Allen and Elledge 1994), which contains the HIS3 and Tn5 neo-selectable markers.

Site-directed mutagenesis was performed to generate a kinase-deficient mutant of sad1. pIA93 was used as a template for PCR to mutate nucleotides 712-714 from AAG (Lys) to GCC (Ala). First, two PCR reactions were carried out to produce overlapping amplified fragments. In reaction 1, wild-type forward primer $\left(5^{\prime}\right)$ CATGCCATGGGTAGAAACCCAGCCTGTGAC $\left(3^{\prime}\right)$ and mutagenic reverse primer $\left(5^{\prime}\right)$ ACTTATAATGGCCACCGCGAATGTTTTC $\left(3^{\prime}\right)$ were used. In reaction 2, mutagenic forward primer $\left(5^{\prime}\right)$ GGGAAAACATTCGCGGTGGCCATTATAAGTAAA $\left(3^{\prime}\right\}$ and wild-type reverse primer $\left(5^{\prime}\right)$ GCTCTAGATTATTGAGCATCGTCCATATTTTC $\left(3^{\prime}\right)$ were used. PCRderived products were recovered from agarose gels, and $10 \mathrm{ng}$ of each were combined and amplified using wild-type forward and reverse primers. The full length PCR-derived fragment was digested with $X$ hoI and $B a m H I$, and the resulting $1.2-\mathrm{kb}$ fragment was subcloned into Xhol-BamHI-cleaved pBS KSII+ for sequencing to confirm the presence of the mutant codon and the absence of other PCR-induced mutations. The 1.2-kb BgIIIBamHI fragment from PCR-mutagenized product was subcloned into BglII-BamHI-digested pJA93 to give pJA104. The 1.7-kb StyI fragment from pJA93 was subcloned into the StyI site of pJA104 to give pJA105. In addition, the $2.4-\mathrm{kb}$ SacI fragment from pJA93 was subcloned into SacI-digested pJA105 to give pJA106. A site-directed mutagenized sad1 allele (sad1-11 K227A) under control of the endogenous $S A D 1$ promoter was generated in a three-way ligation using the $0.5 \cdot \mathrm{kb} K p n I-B g I I I$ fragment from pIA93, the $3.2-\mathrm{kb} B g / 1 \mathrm{H}-\mathrm{XbaI}$ fragment from pJA106, and KpnI-XbaI-digested pUN70 (Elledge and Davis 1988).

pJA103 (CKS1 URA3) was made by ligating the $2.2-\mathrm{kb} S m a \mathrm{I}$ URA3 neo fragment from pJA53 (Allen and Elledge 1994) into EcoRV-cleaved pSE271:CKS1 (Tang and Reed 1993).

\section{Southern and Northern blot analysis}

DNA probes were labeled by the hexamer primer method (Feinberg and Vogelstein 1983). Hybridizations for Southern blots were carried out as described previously (Elledge and Davis 1987). Yeast RNA was isolated using the hot phenol method (Kohrer and Domdey 1991). RNA was resolved on formaldehyde-1.2\% agarose gels (Sambrook et al. 1989), and hybridizations were carried out as described for Southern analysis.

\section{Acknowledgments}

We thank S. Reed, M. Kuroda, S. Sazer, W. Harper, V. Lundblad, G. May, T. Navas, T. Weinert, L. Hartwell, and A. Carr for comments, helpful discussions, and/or reagents. We thank D. Achille for DNA sequencing and Sonal Amin for assistance in the preliminary screen. This work was supported by a National Institutes of Health grant GM44664 and a Welch Foundation grant to S.J.E. Z.Z. is a Welch Foundation predoctoral fellow. S.J.E. is a Pew scholar in the biomedical sciences and an investigator of the Howard Hughes Medical Institute. 
The publication costs of this article were defrayed in part by payment of page charges. This article must therefore be hereby marked "advertisement" in accordance with 18 USC section 1734 solely to indicate this fact.

\section{References}

Al-Khodairy, F. and A.M. Carr. 1992. DNA repair mutants defining G2 checkpoint pathways in Schizosaccharomyces pombe. $E M B O$ I. 11: 1343-1350.

Allen, J.B. and S.J. Elledge. 1994. A family of vectors that facilitate transposon and insertional mutagenesis of cloned genes in yeast. Yeast (in press).

Amon, A., U. Surana, L. Muroff, and K. Nasmyth. 1992. Regulatin of $\mathrm{p} 34^{\mathrm{CDC} 28}$ phosphorylation is not required for entry into mitosis in $S$. cerevisiae. Nature 355: 368-371.

Cohen, M.M. and H.P. Levy. 1989. Chromosome instability syndromes. Adv. Hum. Genet. 18: 43-149.

El-Deiry, W.S., T. Tokino, V.E. Velculescu, D.B. Levy, R. Parsons, J.M. Trent. D. Lin, W.E. Mercer, K.W. Kinzler, and B. Vogelstein. 1993. WAF1, a potential mediator of p53 tumor suppression. Cell 75: 817-825.

El-Deiry, W.S., J.W. Harper, P.M. O'Connor, V. Velculescu, C.E. Canman, J. Jackman, J. Pietenpol, M. Burell, D.E. Hill, W.E. Mercer, M.B. Kastan, K.W. Kohn, S.J. Elledge, K.W. Kinzler, and B. Vogelstein. 1994. WAF1/CIP1 is induced in p53-mediated G1 arrest and apoptosis. Cancer Res. 54: 1169-1174.

Elledge, S.J. and R.W. Davis. 1987. Identification and isolation of the gene encoding the small subunit of ribonucleotide reductase from Saccharomyces cerevisiae: A DNA damage inducible gene required for mitotic viability. Mol. Cell. Biol. 7: 2783-2793.

. 1988. A family of versatile centromeric vectors designed for use in the sectoring-shuffle mutagenesis assay in Saccharomyces cerevisiae. Gene 70: 303-312.

- 1990. Two genes, differentially regulated by DNA damage and the cell cycle, encode alternate regulatory subunits of ribonucleotide reductase. Genes \& Dev. 4: 740-751.

Enoch, T. and P. Nurse. 1991. Coupling $M$ phase and S phase: Controls maintaining the dependence of mitosis on chromosome replication. Cell 65: 921-923.

Enoch, T., A. Carr, and P. Nurse. 1992. Fission yeast genes involved in coupling mitosis to completion of DNA replication. Genes \& Dev. 6: 2035-2046.

Feinberg, A.P. and B. Vogelstein. 1983. A technique for radiolabeling DNA restriction endonuclease fragments to high specific activity. Anal. Biochem. 132: 6-13.

Gould, K.L. and P. Nurse. 1989. Tyrosine phosphorylation of the fission yeast $c d c 2^{+}$protein kinase regulates entry into mitosis. Nature 342: 39-45.

Gu, Y., C.W. Turck, and D.O. Morgan. 1993. Inhibition of CDK2 activity in vivo by an associated $20 \mathrm{~K}$ regulatory subunit. Nature 366: 707-710.

Hadwiger, J.A., C. Wittenberg, M.D. Mendenhall, and S.I. Reed. 1989. The Saccharomyces cerevisiae CKS1 gene, a homolog of the Schizosaccharomyces pombe suc1 ${ }^{+}$gene, encodes a subunit of the Cdc28 protein kinase complex. Mol. Cell. Biol. 9: 2034-2041.

Harper, J.W., G.R. Adami, N. Wei, K. Keyomarsi, and S.J. Elledge. 1993. The p21 Cdk-interacting protein Cipl is a potent inhibitor of $\mathrm{Gl}$ cyclin-dependent kinases. Cell 75: 805-816.

Hartwell, L. 1992. Defects in a cell cycle checkpoint may be responsible for the genomic instability of cancer cells. Cell 71: 543-546.
Hartwell, L.H. and T.A. Weinert. 1989. Checkpoints: Controls that ensure the order of cell cycle events. Science 246: 229234.

Hoyt, M.A., L. Totis, and B.T. Roberts. 1991. S. cerevisiae genes required for cell cycle arrest in response to loss of microtubule function. Cell 66: 507-517.

Hutter, K.J. and H.E. Eipel. 1979. DNA determination of yeast by flow cytometry. I. Gen. Microbiol. 113: 369-375.

Ito, H., Y. Fukada, K. Murata, and A. Kimura. 1983. Transformation of intact yeast cells with alkali cations. J. Bacteriol. 153: 163-168.

Johnston, L.H. and K.A. Nasmyth. 1978. Saccharomyces cere-

- visiae cell cycle mutant $c d c 9$ is defective in DNA ligase. Nature 274: 891-893.

Kastan, M.B., Q. Zhan, W.S. El-Deiry, F. Carrier, T. Jacks, W.V. Walsh, B.S. Plunkett, B. Vogelstein, and A.J. Fournace Jr. 1992. A mammalian cell cycle checkpoint pathway utilizing p53 and GADD45 is defective in Ataxia-Telangiectasia. Cell 71: 587-597.

Kelly, T.J., G.S. Martin, S.L. Forsburg, R.J. Stephen, A. Russo, and P. Nurse. 1993. The fission yeast $c d c 18^{+}$gene product couples S phase to START and mitosis. Cell 74: 371-382.

Kilmartin, J.V. and A.E.M. Adams. 1984. Structural rearrangements of tubulin and actin during the cell cycle of the yeast Saccharomyces. I. Cell Biol. 98: 922-933.

Kohrer, K. and H. Domdey. 1991. Preparation of high molecular weight RNA. Methods Enzymol. 194: 398-405.

Kuerbitz, S.J., B.S. Plunkett, W.V. Walsh, and M.B. Kastan. 1992. Wild type p53 is a cell cycle checkpoint determinant following irradiation. Proc. Natl. Acad. Sci. 89: 7491-7495.

Kusubata, M., T. Tokui, Y. Matsuoka, E. Okumura, K. Tachibana, S. Hisanaga, T. Kishimoto, H. Yasuda, M. Kamijo, Y. Ohba, K. Tsujimura, R. Yatani, and M. Inagaki. 1992. pl3 ${ }^{\text {sucl }}$ suppresses the catalytic function of $\mathrm{p} 34^{\text {cdc2 }}$ kinase for intermediate filament proteins, in vitro. $/$. Biol. Chem. 267: 20937-20942.

Li, J.J. and R.J. Deshaies. 1993. Exercising self-restraint: Discouraging illicit acts of $\mathrm{S}$ and $\mathrm{M}$ in eukaryotes. Cell 74: 223226.

Li, R. and A.W. Murray. 1991. Feedback control of mitosis in budding yeast. Cell 66: 519-531.

Livingstone, L.R., A. White, J. Sprouse, E. Livanos, T. Jacks, and T.D. Tisty. 1992. Altered cell cycle arrest and gene amplification potential accompany loss of wild-type p53. Cell 70: 923-935.

Murray, A.W. 1992. Creative blocks: Cell-cycle checkpoints and feedback controls. Nature 359: 599-604.

Nagasawa, H., S.A. Latt, M.E. Lalande, and J.B. Little. 1985. Effects of X-irradiation on cell cycle progression, induction of chromosomal aberrations and cell killing in Ataxia Telangiectasia. Mutat. Res. 148: 71-82.

Nurse, P. 1990. Universal control mechanism regulating onset of M-phase. Nature 344: 503-508.

Osmani, S.A., R.T. Pu, and N.R. Morris. 1988. Mitotic induction and maintenance by overexpression of a G2-specific gene that encodes a potential protein kinase. Cell 53: 237244.

Painter, R.B. and B.R. Young. 1980. Radiosensitivity in Ataxia Telangiectasia: A new explanation. Proc. Natl. Acad. Sci. 77: 7315-7317.

Ramer, S.W., S.J. Elledge, and R.W. Davis. 1993. Dominant genetics using a yeast genomic library under the control of a strong inducible promoter. Proc. Natl. Acad. Sci. 89: 1158911593.

Rao, P.N. and R.T. Johnson. 1970. Mammalian cell fusion studies on the regulation of DNA synthesis and mitosis. Nature 
225: 159-164.

Roberge, M. 1992. Checkpoint controls that couple mitosis to completion of DNA replication. T.I.C.B. 2: 277-281.

Rose, M.D., F. Winston, and P. Heiter. 1990. Methods in yeast genetics, a laboratory course manual. Cold Spring Harbor Laboratory Press, Cold Spring Harbor, New York.

Rowley, R., S. Subramani, and P.G. Young. 1992. Checkpoint controls in Schizosaccharomyces pombe: rad1. EMBO $I$. 10: $1335-1342$

Rudolph, N.S. and S.A. Latt. 1989. Flow cytometric analysis of X-ray sensitivity in Ataxia Telangiectasia. Mutat. Res. 211: $31-41$.

Saka, Y. and M. Yanagida. 1993. Fission yeast $\mathrm{cut5}^{+}$, required for $S$ phase onset and $M$ phase restraint, is identical to the radiation-damage repair gene rad4 ${ }^{+}$. Cell 74: 383-393.

Salah-ud-Din, S.J. Brill, M.P. Fairman, and B. Stillman. 1990. Cell-cycle-regulated phosphorylation of DNA replication factor A from human and yeast cells. Genes \& Dev. 4: 968977.

Sambrook, J., E.F. Fritsch, and T. Maniatis. 1989. Molecular cloning: A laboratory manual, 2nd ed. Cold Spring Harbor Laboratory Press, Cold Spring Harbor, New York.

Sanger, F., S. Nicklen, and A.R. Coulson. 1977. DNA sequencing with chain-terminating inhibitors. Proc. Natl. Acad. Sci. 87: 2916-2920.

Siede, W., A.S. Friedberg, and E.C. Friedberg. 1993. RAD9-dependent G1 arrest defines a second checkpoint for damaged DNA in the cell cycle of Saccharomyces cerevisiae. Proc. Natl. Acad. Sci. 90: 7985-7989.

Sherman, F., G.R. Fink, and C.W. Lawrence. 1979. Methods in yeast genetics. Cold Spring Harbor Laboratory, Cold Spring Harbor, New York.

Shinohara, A., H. Ogawa, and T. Ogawa. 1992. Rad51 protein involved in repair and recombination in $S$. cerevisiae is a RecA-like protein. Cell 69: 457-470.

Sorger, P.K. and A.W. Murray. 1992. S-phase feedback control in budding yeast independent of tyrosine phosphorylation of p34 ${ }^{C D C 28}$. Nature 355: 365-368.

Stern, D.F., P. Zheng, D.R. Beidler, and C. Zerillo. 1991. Spk1, a new kinase from Saccharomyces cerevisiae, phosphorylates proteins on serine, threonine, and tyrosine. Mol. Cell. Biol. 11: $987-1001$.

Stueland, C.S., D.J. Lew, M.J. Cismowski, and S.I. Reed. 1993. Full activation of $\mathrm{p} 34^{\mathrm{CDC} 8}$ histone $\mathrm{Hl}$ kinase activity is unable to promote entry into mitosis in checkpoint-arrested cells of the yeast Saccharomyces cerevisiae. Mol. Cell. Biol. 13: $3744-3755$

Tang, Y. and S.I. Reed. 1993. The Cdk-associated protein Cks1 functions both in $\mathrm{G}_{1}$ and $\mathrm{G}_{2}$ in Sacchromyces cerevisiae. Genes \& Dev. 7: 822-832.

Walker, G.C. 1987. The SOS response of E. coli. In Escherichia coli and Salmonella typhimurium: Cellular and molecular biology (ed. F.C. Neidhart), pp. 1346-1357. American Society for Microbiology, Washington, D.C.

Weinert, T.A. 1992. Dual cell cycle checkpoints sensitive to chromosome replication and DNA damage in a budding yeast Saccharomyces cerevisiae. Radiat. Res. 132: 141-143.

Weinert, T.A. and L.H. Hartwell. 1988. The RAD9 gene controls the cell cycle response to DNA damage in Saccharomyces cerevisiae. Science 241: 317-322.

- 1993. Cell cycle arrest of $c d c$ mutants and specificity of the RAD9 checkpoint. Genetics 134: 63-80.

Weinert, T.A., G.L. Kiser, and L.H. Hartwell. 1994. Mitotic checkpoints in budding yeast and the dependence of mitosis on DNA replication and repair. Genes \& Dev. 8: 652-665.

Xiong, Y., G. Hannon, H. Zhang, D. Casso, R.E. Kobayashi, and
D. Beach. 1993. p21 is a universal inhibitor of cyclin-dependent kinases. Nature 366: 701-704.

Yin, Y., M.A. Tainsky, F.Z. Bischoff, L.C. Strong, and G.M. Wahl. 1992. Wild-type p53 restores cell cycle control and inhibits gene amplification in cells with mutant p53 alleles. Cell 70: 937-948.

Zambetti-Bosseler, F. and D. Scott. 1981. Cell death, chromosome damage and mitotic delay in normal human, Ataxia Telangiectasia, and Retinoblastoma fibroblasts after X-irradiation. Int. I. Radiat. Biol. 39: 547-558.

Zheng, P., D.S. Fay, J. Burton, H. Xiao, J.L. Pinkham, and D.F. Stern. 1993. SPK1 is an essential S-phase-specific gene of Saccharomyces cerevisiae that encodes a nuclear serine/ threonine/tyrosine kinase. Mol. Cell. Biol. 13: 5829-5842.

Zhou, Z. and S.J. Elledge. 1993. DUN1 encodes a protein kinase that controls the DNA damage response in yeast. Cell 75: 1119-1127. 


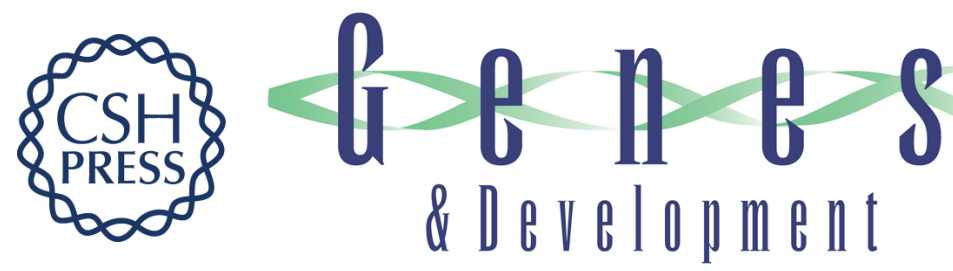

\section{The SAD1/RAD53 protein kinase controls multiple checkpoints and DNA damage-induced transcription in yeast.}

J B Allen, Z Zhou, W Siede, et al.

Genes Dev. 1994, 8:

Access the most recent version at doi:10.1101/gad.8.20.2401

References This article cites 58 articles, 19 of which can be accessed free at:

http://genesdev.cshlp.org/content/8/20/2401.full.html\#ref-list-1

License

Email Alerting

Service

Receive free email alerts when new articles cite this article - sign up in the box at the top right corner of the article or click here.

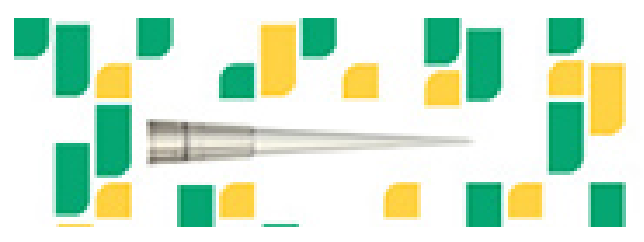

Focused on your science. 